\title{
Methods of amorphization and investigation of the amorphous state
}

\author{
TOMAŽ EINFALT* \\ ODON PLANINŠEK \\ KLEMEN HROVAT \\ University of Ljubljana, Faculty of \\ Pharmacy, 1000 Ljubljana, Slovenia
}

Accepted April 26, 2013
The amorphous form of pharmaceutical materials represents the most energetic solid state of a material. It provides advantages in terms of dissolution rate and bioavailability. This review presents the methods of solid-state amorphization described in literature (supercooling of liquids, milling, lyophilization, spray drying, dehydration of crystalline hydrates), with the emphasis on milling. Furthermore, we describe how amorphous state of pharmaceuticals differ depending on the method of preparation and how these differences can be screened by a variety of spectroscopic (X-ray powder diffraction, solid state nuclear magnetic resonance, atomic pairwise distribution, infrared spectroscopy, terahertz spectroscopy) and calorimetry methods.

Keywords: amorphous solid preparation, crystallinity, spectroscopy, calorimetry

The existence of drugs and excipients in multiple physical forms (e.g., polymorphs) provides pharmaceutical scientists with an opportunity to select the preferred form of the material to be used in a formulation. This is very useful since critical properties, such as particle morphology and dissolution properties, are frequently different in the different physical forms of a material. The amorphous form of pharmacologically active materials has received considerable attention because, in theory, it represents the most energetic solid state of a material, and should thus provide the biggest advantages in terms of dissolution rate and bioavailability (1). However, the amorphous form also shows various disadvantages, such as lower physical stability compared to crystals.

The structure of an amorphous solid is usually described as possessing a crystal-like short-range molecular arrangement, but lacking a long-range order. As illustrated by Fig. 1, the immediate environment of a molecule $(\mathrm{m})$ in an amorphous solid may not differ significantly from that in a crystal (e.g., similar number of and distance to nearest neighbors), but an amorphous solid lacks any long-range transational-orientational symmetry that characterizes a crystal (1). However, this is only true when we are dealing

\footnotetext{
* Correspondence; e-mail: tommy.einfalt@gmail.com
} 


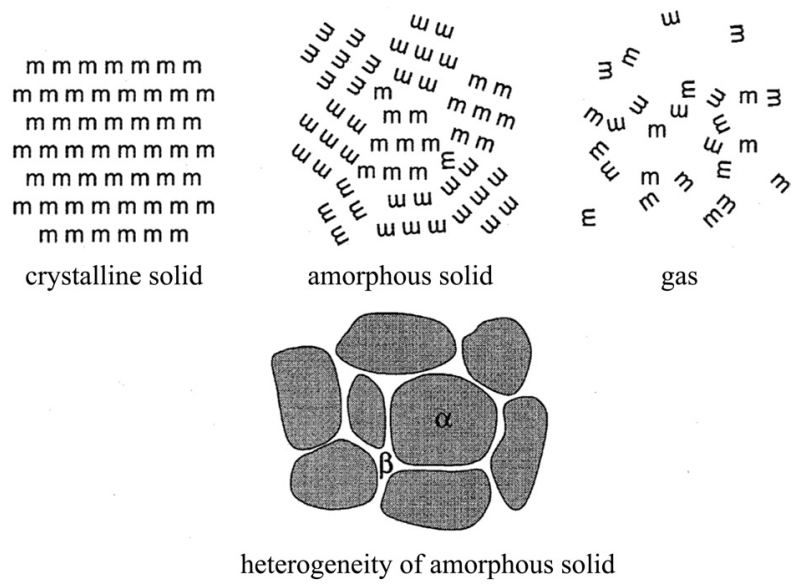

Fig. 1. Schematic representation of the structure of an amorphous and a crystalline solid. Molecular arrangement in the amorphous solid is not totally random, like in the gas phase, but features a short-range molecular order similar to that in the crystalline one. According to some models, an amorphous solid has distinct regions (e.g., $\alpha$ and $\beta$ ), which have different densities and thermal relaxation behaviors (i.e., the time scale for long-range molecular motion). Adapted from ref. 2 with permission.

with non-ionic material and substances that do not form strong intermolecular connections with water.

In Fig. 2, the enthalpy $(H)$ or specific volume $(V)$ of a solid substance is plotted as a function of temperature. For crystalline material, at very low temperatures we see a small increase in enthalpy and volume with respect to temperature, which is indicative of a certain heat capacity $\left(C_{\mathrm{p}}\right)$ and thermal expansion coefficient. There is a discontinuity in both $H$ and $V$ at the melting temperature $T_{\mathrm{m}}$ representing the first order phase transition to the liquid state. Upon rapid cooling of the melt, the values of $H$ and $V$ may follow

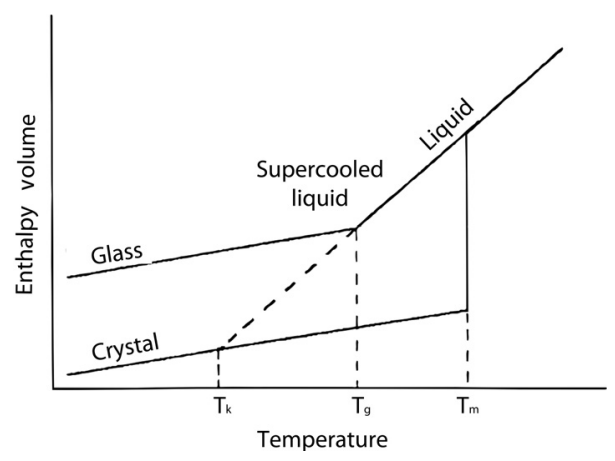

Fig. 2. Schematic description of the variation in enthalpy (or volume) with temperature $T_{\mathrm{m}}, T_{\mathrm{g}}, T_{\mathrm{k}}$. Adapted from ref. 1 with permission. 
the equilibrium line for the liquid beyond the melting temperature into a »super-cooled liquid « region. On further cooling, a change in slope is usually seen at the characteristic temperature known as the glass transition temperature $\left(T_{\mathrm{g}}\right)$. At $T_{\mathrm{g}}$, the properties of the glassy material deviate from those of the equilibrium super-cooled liquid to give a non-equilibrium state having even higher $H$ and $V$ than the super-cooled liquid. The Kauzmann temperature $\left(T_{\mathrm{k}}\right)$ is thought to mark the lower limit of the experimental glass transition $\left(T_{\mathrm{g}}\right)(1)$.

Amorphous materials have higher Gibbs free energy than their crystalline counterparts, and as a result have higher apparent solubility and faster dissolution rates, which in turn can lead to higher bioavailability for drugs that exhibit dissolution-rate limited absorption (classified according to the Biopharmaceutical Classification System (BSC) as class II drugs) (3). However, due to excess entropy, enthalpy and free energy that account for better solubility, the amorphous state is inherently unstable and recrystallization may occur (2).

\section{METHODS OF AMORPHIZATION}

The most common techniques of preparing amorphous forms in pharmaceutical systems (e.g., pure drugs or polymer glass solutions) can be categorized according to two principal transformation mechanisms. In most cases, crystalline material is intermediately transformed into a thermodynamically unstable non-crystalline form (either a melt or a solution). Further, the thermodynamically unstable amorphous solid material is prepared by quench cooling of the melt or rapid precipitation from solution, e.g., spray drying. The other transformation mechanism involves direct solid conversion from the crystalline to the amorphous form. The best example is mechanical activation such as milling. Whilst when melt and solution mediated methods are used all crystallinity is lost in the intermediate phase (melt, solution), mechanical activation methods may not cause complete disruption of the molecular order $(1,4-6)$.

It should also be noted that differently prepared amorphous form exhibits different properties. Salvonien et al. (7) have found that the cryo-milled simvastatin has lower stability and a reduced recrystallization rate than quench cooled samples of the same substance. In comparison, Karmwar et al. (8) found that the cryo-milled amorphous form of indomethacin is the least stable compared to amorphous form prepared by quench cooling and spray drying. Moreover, it should be noted, the differences between the differently prepared amorphous forms are not only in the stability but can be detected on the molecular level using terahertz spectroscopy or solid state $\operatorname{NMR}(\mathrm{ss}-\mathrm{NMR})(9,10)$.

The term polyamorphism has been used to describe amorphous states produced by different annealing times or preparative routes. An example are glasses that have been aged below $T_{\mathrm{g}}$ for different times and hence developed various degrees of »relaxation enthalpy", that is, the enthalpy of an aged amorphous substance (2). The term polyamorphism has also been used in literature to describe the existence of distinct amorphous phases separated by first-order phase transitions $(4,11)$. Patterson et al. (12) have shown that the susceptibility to amorphous conversion by different methods is compound specific. Therefore if amorphous conversion is required, there is merit in investigating the use of more than one preparative technique. 
Besides the possibility of the existence of polyamorphs for pharmaceutically relevant substances, the concept of a rigid amorphous fraction (RAF) has also been introduced. RAF is believed to be an intermediate between the crystalline and amorphous phases. The striking difference between RAF and the "true " amorphous fraction lies in the change of heat capacity $\left(\Delta C_{\mathrm{p}}\right)$ at the glass transition $\left(T_{\mathrm{g}}\right)$. As RAF is more closely associated with the crystalline state, it does not undergo a change in $C_{\mathrm{p}}$ and $T_{\mathrm{g}}$. This implies that an amorphous form containing RAF will exhibit a smaller change in $C_{p}$ and $T_{p}$ than the same amorphous substance without RAF (13). Solid-state amorphization will be the main topic addressed in this paper.

\section{Solution based methods of amorphization}

Melting and quench cooling. - Melting and quench cooling of a crystalline drug to produce an amorphous product is a relatively simple technique. Upon cooling of the molten drug below the freezing point, molecular motion is slowed down. If cooling of the molten drug takes place fast enough, the molecules are not able to rearrange into a crystalline lattice; therefore, they are "frozen « in a more disordered state and crystallization is avoided $(14,15)$. The slower a liquid is cooled, the longer is the time available for configurational sampling at each temperature, and the colder it can become before falling out of liquid (7). Therefore the enthalpy of the end product depends on the cooling rate (16) although it must be noted that if the cooling rate is too slow, the product will crystallize. The drawback of this approach is its potential for chemical degradation during the melting step due to high temperatures, since the degradation products may lower the glass transition temperature of the amorphous product (17). Thermal degradation is compound dependent and only limited steps can be taken to overcome this problem, such as heating under an inert gas (12). So far, a range of pharmaceutical active substances and excipients have been successfully amorphized by melting and quenching (18-21).

Spray drying. - The spray drying technique may be suitable for obtaining the amorphous form of the drug substance, either alone or in combination with the polymer (2225). It converts a liquid solution into a powder in one step (26). Concentrated liquid is pumped to the atomizing device where it is broken into small droplets. These droplets meet a stream of hot air and lose the solvent very rapidly while still suspended in dry air. Components of the concentrated liquid may not crystallize immediately when their solubility limit is reached at the droplet surface. In this case, a fully or partially amorphous solid is formed (27). Drugs that have a relatively low $T_{\mathrm{g}}$ make it very difficult to obtain a stable amorphous product in the form of free flowing powder by spray drying. As the outlet temperature rises above the $T_{\mathrm{g}}$, there is always a possibility that the final product is present in the super cooled rubbery state. Also, such product is often sticky or tacky, which causes a decrease in product recovery and hampers its handling in subsequent processes (22). Spray drying has been commonly used in the past decade as a technique for preparing amorphous active substances and excipients (28-31).

Freeze-drying. - Freeze-drying, also known as lyophilization, has been used for a number of years as a pharmaceutical unit operation for the low temperature drying of injectable systems (32). Freeze-drying involves desiccation of a substance by crystalliza- 
tion of water, followed by sublimation of water vapor from the solid state at reduced pressure. Depending on the cooling rate, some solutes may crystallize during the freezing stage. Those solutes which do not crystallize are converted to amorphous solids when the temperature drops below the $T_{\mathrm{g}}$ of the maximally concentrated solute. At the end of a freeze-drying process, when the solvent is completely removed through sublimation, the freeze-dried formulation exists as an amorphous or partially amorphous system. The $T_{\mathrm{g}}$ of a freeze-dried formulation is determined by components of the formulation and the presence of residual water, which can act as a plasticizer lowering the glass transition temperature (33). The process has been recently utilized to produce amorphous trehalose and itraconazole $(34,35)$.

\section{Solid state amorphization}

Dehydration of crystalline hydrates. - Dehydration of crystalline hydrates has been demonstrated as a feasible and "gentle " route to the amorphous state of organic solids. Saleki-Gerhardt et al. (5) showed that heating crystalline raffinose pentahydrate at $60{ }^{\circ} \mathrm{C}$ in vacuum converts the material to an amorphous form identical to the one produced by freeze-drying (5). Li et al. (36) observed that crystalline carbamazepine dihydrate becomes amorphous upon dehydration at $45{ }^{\circ} \mathrm{C}$ with $\mathrm{N}_{2}$ purge. The resulting amorphous solid undergoes a glass transition at $56{ }^{\circ} \mathrm{C}$, which is markedly above the drying temperature $\left(45^{\circ} \mathrm{C}\right)$, and crystallizes on further heating $\left(\right.$ at $\left.86^{\circ} \mathrm{C}\right)$. These studies indicate that apart from being a potential route to amorphous solids, the drying of crystalline hydrates may reduce their physicochemical stability through loss of crystallinity. More recently, Sussich et al. (37) investigated the amorphization of a di-hydrate crystalline polymorph of trehalose upon dehydration.

Milling. - Milling, also known as comminution or grinding, is typically regarded as a particle size reduction process across many industries, including the manufacturing of pharmaceuticals and fine chemicals $(38,39)$. In secondary pharmaceutical processing, it is often used to increase the specific surface area of poorly water-soluble drugs to improve their dissolution properties and bioavailability (40). There is a variety of different commercially available milling equipment that can be utilized for the communition of pharmaceuticals. In general, the devices can be subdivided into three main categories, based on how energy is transferred to the material to be ground: ball mills, shear action mills and shock action mills. In the case of ball mills, energy is transferred to the ground material by mill bodies or impellers. The material is exposed to both shear and normal stresses. On the other hand, in shear action mills, the material is ground by crushing elements (solid surfaces in relative motion). Shock action mills transfer the energy directly to the milled material. In this case, material is milled by direct collision of particles. However, besides reducing the particle size, the milling process is often accompanied by other unintended effects such as changes in morphology (41), crystallinity (41), polymorphism (42), glass transition temperatures (43), chemical stability (44) and melting behavior (45) during subsequent post-milling storage. The process of milling is very energy-consuming. Furthermore, the high energy output could result in degradation of the milled substance and the milling equipment. Milling is also used for more specific applications such as preparation of co-crystals $(46,47)$. Pharmaceutical literature describes numerous examples of organic compounds like piroxicam (48), budesonide (49), sucrose 
$(50,51)$, lactose $(52,53)$, trehalose $(54,55)$, that become partially or completely amorphous when submitted to milling. However, it appears that one of the disadvantages of amorphization through milling is that the $T_{\mathrm{g}}$ of the milled substance plays a fundamental role and sufficiently low temperatures of milling $\left(T_{\text {mill }}\right)$ must therefore be provided to induce amorphization through milling (56).

Principles of solid-state amorphization through milling. - There are several competing ideas as to how the transformation from the crystalline to the amorphous state takes place during milling. A commonly held view is that amorphization occurs via generation of localized heating effects followed by quenching. Alternatively, Okamoto et al. (57) suggest that milling leads to an increase in static disorder that adds to the intrinsic dynamic disorder inherent within the lattice up to critical value where the structural collapse occurs. Others argue that the disordering process is best regarded as an accumulation of defects (or, viewed another way, a dramatic reduction in crystallite size) and hence may not necessarily be regarded as amorphization in the traditional sense (58). Some of the advantages of cryogenic milling are that it is a mild method of producing amorphous material without the use of solvents or melting.

Influence of temperature on solid-state amorphization through milling. - The group of Descamps et al. $(52,59,60)$ provides a very significant contribution on how the previously mentioned theories apply to organic crystalline materials. They have highlighted the relationship between the temperature of milling and the glass transition temperature of the corresponding material. In particular, they have demonstrated that cryo-milling (well below $T_{\mathrm{g}}$ ) results in amorphization and milling above $T_{\mathrm{g}}$ results in polymorphic transformation. This contradicts the melt-quenching explanation. These authors favor the concept of driven materials, as outlined by Martin and Bellon (61). In brief, the approach suggests that in milling a material there is a temperature independent disordering process induced by ballistic interactions, which competes with the temperature dependent restoration process. The balance of these two processess is expressed in terms of an "effective" temperature $T_{\text {eff, }}$ which is the temperature at which the non-milled material would assume the same level of disorder as the milled one. A milling process that resulted in a $T_{\text {eff }}$ above the melting point would therefore be expected to result in amorphization. The value of $T_{\text {eff }}$ may be estimated by $E q$. (1) where $T$ is the temperature of milling, $D_{\text {bal }}$ is the (temperature independent) ballistic diffusion coefficient and $D_{\text {th }}$ is the thermal diffusion coefficient corresponding to the restorative process.

$$
T_{\text {eff }}=T\left(1+D_{\text {ball }} / D_{\text {th }}\right)
$$

It is significant that this theory predicts that at low temperatures $D_{\text {th }}$ becomes small compared to $D_{\text {bal }}$, hence raising $T_{\text {eff. }}$ This then explains the counterintuitive observation that amorphization to a greater extent occurs at lower temperatures (62).

A related question is whether the material generated by cryo-milling behaves in a similar manner to "conventionally « generated amorphous materials. Surprisingly, little is known about the subject, although a thorough study by Crowley and Zografi indicated that cryogenic milling of crystalline indomethacin resulted in amorphous material with similar $T_{\mathrm{g}}$ values but reduced physical stability compared to conventionally generated amorphous indomethacin. The authors ascribed the latter to the presence of residual 
crystalline material (63). Qi et al. (62) have also demonstrated a very marked instability of the cryo-milled material below its $T_{\mathrm{g}}$ and also the possibility of the prepared amorphous materials exhibiting a more complex recrystallization profile than commonly considered for the solid state amorphous form.

The effect of crystal morphology on induced crystal disorder through milling. - One persistent challenge in the development of pharmaceutics is the crystal habit, or morphology. For example, equidimensional crystals are usually preferred in the industry as they have better handling and processing characteristics such as flowability and compactability $(64,65)$. Chikalia et al. (66) have found that $\beta$-succinic acid in a plate-like morphology is more prone to disorder than a needle-like morphology. Crystal morphology engineering and the use of crystals with the most suitable morphology could therefore be a valuable tool to enhance the solid-state transformation.

a)

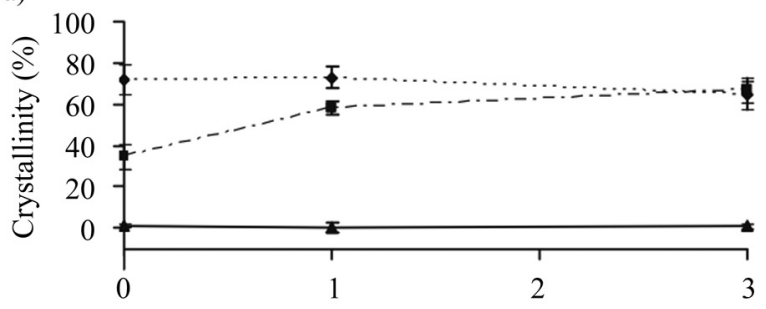

b)

Time (months)
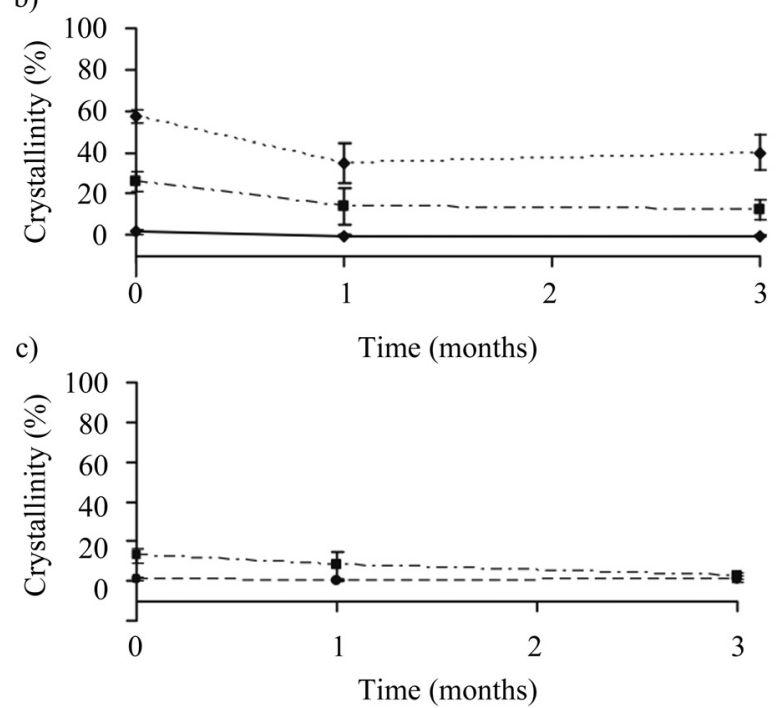

Fig. 3. Indomethacin co-ground with Neusilin in different ratios at $75 \% \mathrm{RH}$ and stored at $40{ }^{\circ} \mathrm{C} / 75$ \% RH: a) 1:1, b) 1:4, c) 1:5. Key: 12 h co-ground, - - - - 3 days co-ground, - - - 5 days co-ground, -8 days co-ground. Adapted from ref. 78 with permission. 
Co-milling. - Co-milling of drugs with excipients has been employed for acceleration of solid amorphization and stabilization of amorphous state. Watanabe et al. (67) showed that amorphization of indomethacin could be achieved by milling it with polyvinylpyrrolidone or silica. Ali et al. (68) used a vibration mill to prepare amorphous co-ground mixtures of flufenamic acid with amorphous calcium silicate and silicon-dioxide. Amorphization of ibuprofen, sulfathiazole, phenothiazine, acridine, chloranil and vitamin K3 has been achieved by co-grinding with polyvinylpyrrolidone (69-71). Amobarbital amorphized in the presence of a variety of excipients such as carbon black, ethyl cellulose, precipitated silica and activated charcoal (72). A variety of other excipients such as $\beta$-cyclodextrin, dextrans, chitin, chitosan, gelatin, polyethylene glycol, methyl cellulose, hydroxyl propyl cellulose, calcium silicate and silicon dioxide were used to amorpize structurally diverse drugs, resulting in various degrees of amorphization (6777). More recently, Bahl et al. (78) have shown that increasing the amount of Neusilin US2 with respect to indomethacin reduced the amorphization time (Fig. 3). The mixture also showed high physical stability.

Time of milling and solid state amorphization. - The crystal to glass conversion upon milling often requires milling times of several hours to complete $(50,54)$. Short milling times are thus expected to induce a size reduction of both the crystallites (small single crystals) and the particles (a particle can be composed of several crystallites) without generating any noticeable amorphous content. Until now, only a few investigations of weakly milled materials have been performed and little is known about the structural and micro-structural states that precede amorphization observed during long and intense milling (79). A very important point is to determine when and how the accumulation of crystalline defects (crystal surfaces, dislocations, vacancies, etc.) upon milling gives rise to a genuine amorphous state, which is, in turn, characterized by chemical disorder. Caron et al. $(10,80,81)$ have studied the structural and thermodynamic changes of crystalline alpha-lactose in the course of its solid-state amorphization by milling. The results revealed that, in the course of the milling process, the material cannot be described as a biphasic system made of both perfect crystalline matter and genuine amorphous matter. It appears to be constituted of a wide panel of structural states more or less disordered and ranging from the crystalline state to the amorphous state. This conceptual difficulty clearly emerges from the results of these authors, who have shown that very different characterization techniques give rise to very different kinetics of amorphization (Table I). Terada et al. (82) have shown that peak intensities of the X-ray powder diffraction (XRPD) patterns of two polymorphs of terfenadine decreased with increasing grinding times (Fig. 4).

Table I. Differences in the time of amorphization depending on the method of solid-state characterization

\begin{tabular}{lccc}
\hline & Indomethacin & Lactose & Trehalose \\
\hline DSC & $120 \mathrm{~min}$ & $50 \mathrm{~h}$ & $10 \mathrm{~h}$ \\
XRPD & $30 \mathrm{~min}$ & $1 \mathrm{~h}$ & No data \\
ss-NMR & $195 \mathrm{~min}$ & $30 \mathrm{~h}$ & $20 \mathrm{~h}$ \\
\hline
\end{tabular}

Adapted from refs. 10, 80, 81 with permission. 


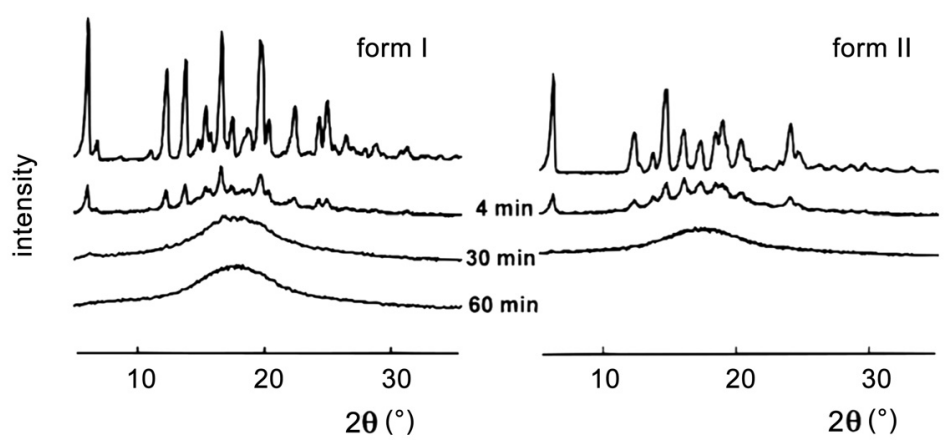

Fig. 4. Change in XRPD patterns of terfenadine (form I and form II) by grinding. Adapted from ref. 82 with permission.

\section{CHARACTERIZATION OF THE AMORPHOUS STATE}

The strategy of characterizing amorphous solids differs from that for crystalline solids. Molecular-level structural elucidation, which is feasible for crystalline solids by diffraction and spectroscopic methods, is less applicable to amorphous solids, and greater emphasis is placed on structural mobility and changes. It is customary to characterize amorphous material both below and above the glass temperature, i.e., both as a frozen solid and a super-cooled viscous liquid. Thus effective characterization of amorphous pharmaceutical products requires a multidisciplinary approach using complementary analytical methods. To characterize pharmaceutical solids, we may use various techniques, such as Raman spectroscopy (RS), Fourier transform infrared spectroscopy (FT-IR) or solid state nuclear magnetic resonance (ss-NMR), which are primarily intramolecular methods probing the sample at the molecular level. Intermolecular information is gained by directly employing techniques such as differential scanning calorimetry (DSC), thermogravimetric analysis (TGA) and XRPD, which analyze the sample on the particulate level. Recently, tetrahertz pulsed spectroscopy (TPS), second harmonic generation (SHG) and ${ }^{14} \mathrm{~N}$ nuclear quadrupole resonance (NQR) have been also used as spectroscopy techniques to directly investigate particulate properties of solids $(81,83-85)$. Other properties associated with the particulate level, such as morphology or size distribution, can be characterized using microscopic techniques such as polarizing light microscopy (PLM) and scanning electron microscopy (SEM) $(84,86)$. These methods offer several types of information about the investigated substance $(87,88)$ :

(i) Structure: The structure of amorphous solids is not random at the molecular level, but may possess short-range order, residual crystallinity, polymorphic states, and regions of different density.

(ii) Thermodynamics: As mentioned before, amorphous solids present higher energy, entropy and free energy when compared to the crystalline state of the same material. Excess properties are parameters included in some theoretical models of crystallization and structural relaxation. 

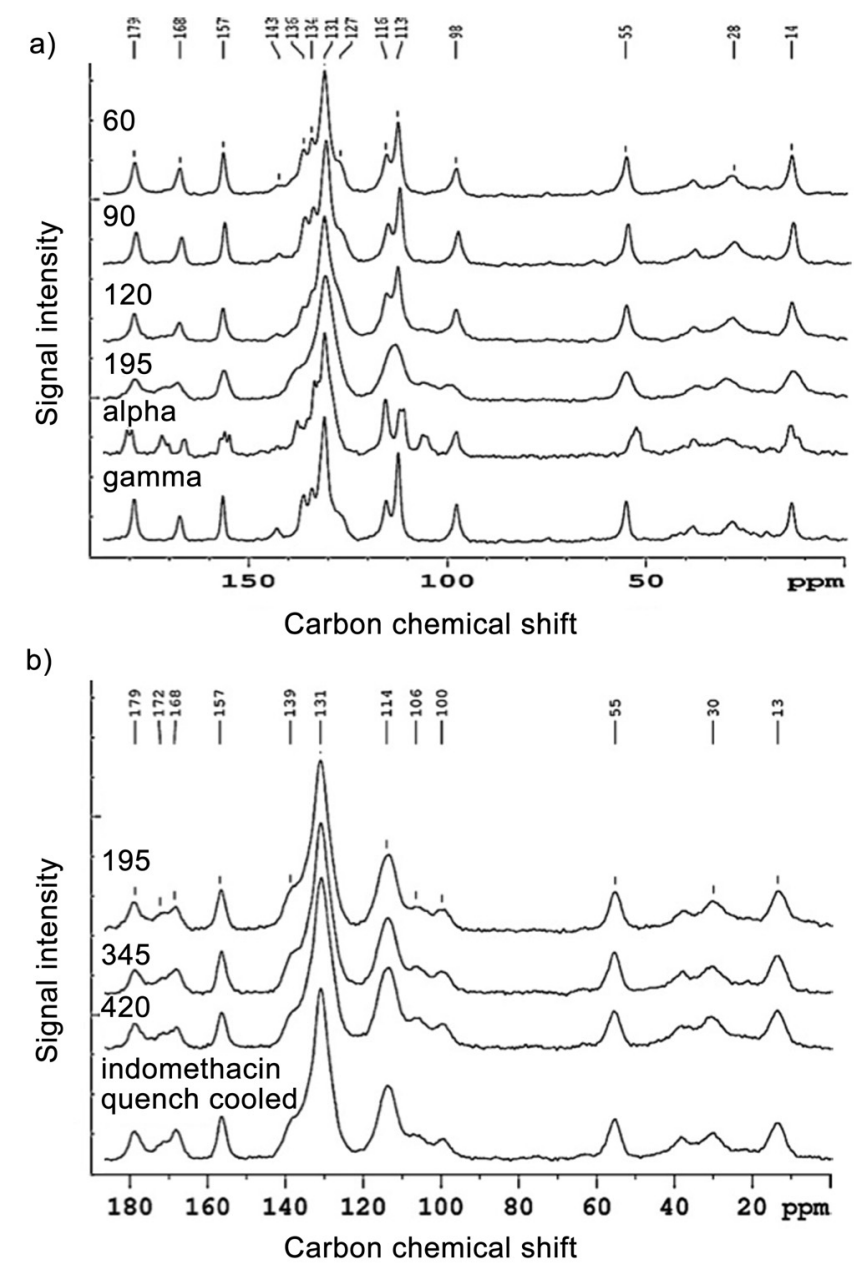

Fig. 5. NMR spectra of a) 60-, 90-, 120-, 195-min cryo-milled samples of $\gamma$-indomethacin and $\alpha$-indomethacin; b) 195-, 345- and 420-min cryo-milled samples of $\gamma$-indomethacin and quench cooled amorphous indomethacin. The quench cooled sample and the cryo-milled samples with increasing time of milling show much broader peaks, which is characteristic of amorphous substances (81). Adapted from ref. 81 with permission.

(iii) Changes: When exposed to the right conditions amorphous solids can crystallize or undergo structural relaxation owning to instability compared to the corresponding crystals and »equilibrium " glasses.

(iv) Multi-component systems: Many pharmaceutical formulations are formed by either active substances and drug excipients or multiple active substances. One or more of the components can be present in the amorphous state. 
SS-NMR

Recently, ss-NMR has been introduced to identify effects such as polymorphism, intra- and inter-molecular hydrogen bonding and tautomerism and is now widely used in conjunction with other analytical techniques (89). High-resolution ${ }^{13} \mathrm{C}$ ss-NMR spectra are obtained using proton decoupling and magic angle spinning (MAS) and sensitivity enhancement is achieved by cross-polarization (CP). ${ }^{13} \mathrm{C}$ ss-NMR has the advantage of being a nondestructive test method that provides information about the structure of the material (90). Furthermore, one of the advantages of ss-NMR is that it is very sensitive to minor conformational changes but is insensitive to particle size. In a ss-NMR study of ranitidine hydrochloride, the authors showed that form II of the drug exhibits molecular disorder crystals and contains two tautomers, nitronic acid and enamine (91). Molecular disorder was attributed to ranitidine hydrochloride solved intermolecular bonding (89). For the characterization of organic substances, the remarkable sensitivity of the ${ }^{13} \mathrm{C}$ chemical shift to local modulations of electronic density has made this technique one of the best probes of conformational aspects. In particular, ${ }^{13} \mathrm{C}$ CPMAS (cross polarization magic angle spinning) appears to be well adapted for studying poly- (or poorly) crystalline solids, revealing qualitative and quantitative features such as identification of phases and structural changes in crystalline polymorphs of pharmaceutical molecules (92-94). Recently, the development of proper analysis methods to measure relative amorphous and crystalline fractions has raised considerable interest $(90,95)$. Lefort et al. (10) have shown, in a study of ball milling trehalose, that an NMR approach can be readily implemented in many situations involving continuous transformations of pure compounds and can still remain a successful method for estimating amorphous content of a sample, even though DSC might fail at it (10). Furthermore, Bøtker et al. (81) utilized ss-NMR to explain the influence of different times of cryo-milling on the amorphization of indomethacin (Fig. 5).

\section{$X$-ray powder diffraction}

The principle behind XRPD experiments is the random orientation of crystals in a substance. If powdered crystals are randomly oriented, then for all sets of planes some of the crystals in the powder will be in the right orientation with respect to the X-ray source to satisfy Bragg's law for proper angle $\theta$. What follows is that at least a few of the mineral grains in the powder will diffract for each of the planes during a scan through angles $\theta$. The more finely ground the powder, the more likely it is that all orientations are sufficiently present. The whole XRPD method is based on the fact that ideally every possible crystalline orientation should be represented equally in a powdered sample. Two main types of powder diffraction experiments are possible according to Smith: automated powder diffractometer experiments yielding (digital) computer output and Debye-Sherer experiments providing (analog) film output. The Debye-Sherer approach uses a camera. A strip of film is wrapped around the powder sample so that diffracted beams from a fixed X-ray source can be recorded for all values of $\theta$ simultaneously. During the measurement, the powder diffractometer moves both the $\mathrm{X}$-ray source and an electronic detector through arcs of $\theta$ values and sends to a computer periodic signals proportional to the averaged diffracted X-ray intensity. Both experiments provide the intensities for diffracted beams as a function of the diffraction angle $\theta$ (or 2 $\theta$ ). The acqui- 
red data is then processed by the Rietveld method in order to minimize the residual function using a non-linear least squares algorithm. With that we can then refine the crystal structure of a compound. XRPD is typically used to determine the occurrence of a non-crystalline solid form, since it can be determined by observing the loss of distinct XRPD peaks characteristic of crystalline order, and the appearance of a general »halo « pattern (1). There are, however, a number of different non-crystalline phases that can give broad halos in the measured XRPD data, the most commonly observed of which are super-cooled liquids and glasses (96). Grinding or milling crystals can remove all traces of crystalinity according to XRPD. Cryo-grinding studies provide an ideal experimental approach to investigate the formation of amorphous material and the nature of the X-ray diffraction response. The typical behavior observed when grinding a crystalline organic material to produce amorphous material is that an increasing percentage of the crystalline material will collapse to amorphous as a function of grinding time. The amorphous local packing generates broad halos in the XRPD pattern that are not correlated to the crystalline peaks. If no significant change is observed in the crystalline diffraction peaks upon grinding, the ground sample can be modeled as a phase separated binary mixture of thermodynamic amorphous and crystalline materials. Although successive micronization should eventually lead to an amorphous structure, a possibility exists that the material has achieved a microcrystalline state, containing crystals so small that they pass the detection of XRD. Johari et al. (97) used DSC to distinguish between amorphous and microcrystalline states based on the presence or absence of glass transition when XRD failed to do so. It should also be noted that materials ground to or exhibiting the same X-ray amorphous pattern might crystallize at different times or to different crystalline forms. This can be perceived as a lack of control, resulting in amorphous materials that are not consistent. A better understanding of short-range and long-range interactions in amorphous materials using atomic pairwise distributions can help explain and possibly control the physical stability of materials. Data analysis of X-ray amorphous patterns plays a significant role in addressing the primary regulatory concerns for drug commercialization: understanding, stability and reproducibility (98).

\section{Atomic pairwise distribution}

The atomic pairwise distribution function (PDF) is a method used to analyze the local structure based on the total scattering pattern from the crystalline, nanocrystalline, quasi crystalline or amorphous materials $(99,100)$. The technique uses the Fourier transformation of XRPD diffractograms to produce a trace in the coordinate system. The $y$ -axis in the PDF graph corresponds to the probability of finding two atoms separated by a distance plotted on the x-axis. In the material science community the PDF technique has been used for several decades (101-105) and has more recently been applied by the pharmaceutical community to study short- and long-range order amorphous glassy materials (106-111). It has been used in studies to investigate crystalline defects, help in the crystal structure determination $(106,107,110)$, characterization of polymer/drug systems (111-113) and the use of multivariate data analysis has alleviated the interpretation of PDF $(108,111)$. It could be a possible route to gain a deeper insight into the degree of disorder in a milled sample. This is due to the fact that PDF displays the probability of finding two atoms separated by a given distance (99). Therefore, it could be expected that with increasing disorder in the sample, the signal amplitude of the PDF trace would 


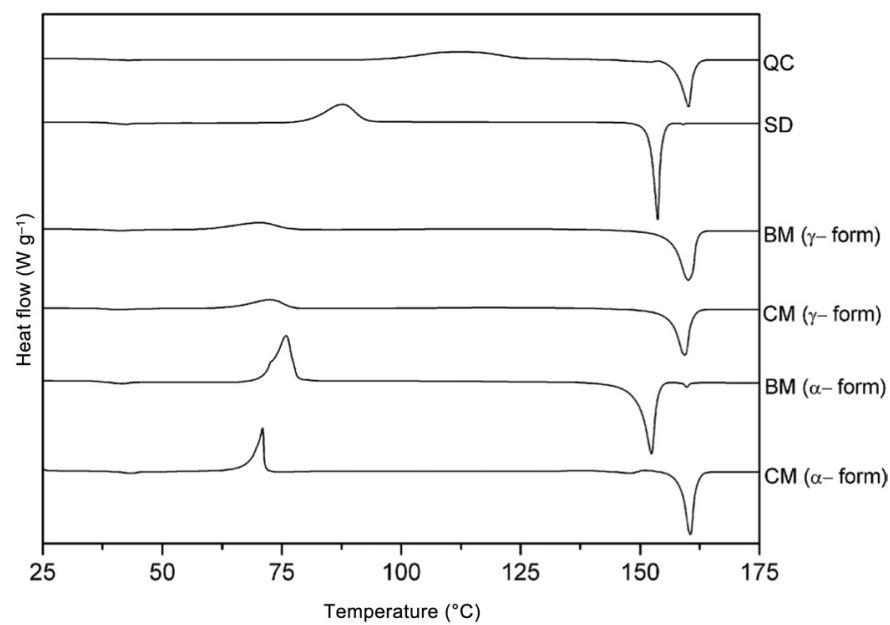

Fig. 6. DSC curves of a freshly prepared amorphous form of indomethacin prepared by different preparative techniques. Key: QC - quench cooled, SD - spray dried, BM - ball milled, CM cryo-milled. Adapted from ref. 8 with permission.

be further reduced, until the highest possible disorder for a given cryo-milling process has been achieved. Bøtker et al. (81) have found that PDF is capable of assessing the minimal cryo-milling time that facilitates the highest degree of disorder and stability in cryo-milled samples of indomethacin.

\section{Differential scanning calorimetry}

Thermal methods have been used for amorphous content determination. DSC is a method commonly used for investigation of phase behavior of pharmaceutical solids, including quantification of the amorphous content (112). Depending on the instrument type, measuring parameters and experimental conditions, there are several methodologies that can be employed to determine the latter. Among them are conventional DSC, modulated temperature DSC (MTDSC) and hyper- or high-speed DSC (HSDSC) (113). Conventional DSC is based on a linear heating rate. In temperature modulated DSC (TMDSC), a small sinusoidal temperature modulation is applied to the sample in addition to the usual linear ramp. In the newest technique, hyper-DSC, controlled fast heating and cooling rates of 50 up to $500{ }^{\circ} \mathrm{C} \mathrm{min}-1$ are used (114). This significantly increases measurement sensitivity because the increased scan rate leads to higher heat flow. Whereas amorphous character can be difficult to detect in highly crystalline solids using the conventional DSC technique, hyper DSC can show glass transitions with enhanced sensitivity and a less time (114).

As mentioned before, amorphous materials exist as solid or liquid glasses like rubbers. The transition between these states is a second-order change phase, which occurs at $T_{\mathrm{g}}(115)$. There are at least three ways to determine $T_{\mathrm{g}}$. Standard $T_{\mathrm{g}}$ is the temperature corresponding to the point on the heat flow curve where the specific heat change is $50 \%$ 
Table II. Thermal properties of amorphous forms of indomethacin prepared by different preparative techniques (8)

\begin{tabular}{lcccc}
\hline Technique & $T_{\mathrm{g}}\left({ }^{\circ} \mathrm{C}\right)$ & $\mathrm{C}_{\mathrm{p}}$ at $T_{\mathrm{g}}\left(\mathrm{J} \mathrm{g}^{-1} \mathrm{~K}^{-1}\right)$ & $\begin{array}{c}\text { Onset of } \\
\text { crystallisation }\left({ }^{\circ} \mathrm{C}\right)\end{array}$ & $\Delta H_{\text {relax }}\left(\mathrm{J} \mathrm{g}^{-1}\right)$ \\
\hline $\mathrm{QC}$ & $42.15 \pm 1.16$ & $0.50 \pm 0.003$ & $96.93 \pm 1.02$ & $1.03 \pm 0.26$ \\
$\mathrm{SD}$ & $41.25 \pm 0.28$ & $0.47 \pm 0.28$ & $73.59 \pm 7.18$ & $0.68 \pm 0.31$ \\
$\mathrm{BM}(\gamma$-form $)$ & $39.23 \pm 2.19$ & $0.57 \pm 0.03$ & $62.14 \pm 4.16$ & $0.28 \pm 0.09$ \\
$\mathrm{CM}(\gamma$-form $)$ & $40.27 \pm 3.57$ & $0.52 \pm 0.16$ & $60.84 \pm 2.91$ & $0.95 \pm 0.84$ \\
$\mathrm{BM}(\alpha$-form $)$ & $37.92 \pm 2.02$ & $0.70 \pm 0.09$ & $70.16 \pm 0.70$ & $0.84 \pm 0.43$ \\
\hline
\end{tabular}

Adapted from ref. 8 with permission.

of the change in complete transition. This is the temperature at which heat capacity is midway between the liquid and glassy state (116). Glass transition can be also regarded as the inflection point of the DSC curve associated with glass transition. If a high relaxation peak follows glass transition, the inflection point of the DSC curve can differ from the real inflection point of the glass transition. Fictive temperature refers to the point on the enthalpy curve where the change of slope occurs (117). The enthalpy curve is the integral of the specific heat curve (Fig. 6). Fictive temperature is the intersection of the extrapolated pre-transition and post-transition baselines on the enthalpy curve.

$\Delta C_{p}$ is linearly proportional to the amorphous content in case that amorphous glasses are in the same state. The largest change in specific heat is equal to the difference between crystalline and rubber states. When glass transition is used for the quantification of amorphous content, there has to be a reference material. The starting point for the development of this method is to ensure that the change in specific heat of a $100 \%$ amorphous sample is reproducible. Many things influence $\Delta C_{\mathrm{p}}$. Glasses are known to change their properties when annealed below their glass transition temperature. The release of relaxation enthalpy that follows glass transition corresponds to the enthalpy difference between annealed and quenched (non-annealed) glass (118). Karmwar et al. (8) have shown that DSC curves of amorphous forms of indomethacin prepared by quench cooling and spray drying exhibit different $T_{\mathrm{g}}$ as shown in Fig. 6 and Table II.

\section{Solution calorimetry}

Few publications have utilized solution calorimetry to determine the extent of drug and excipient crystallinity (119-123). This is a thermal technique in which the temperature change produced by a chemical or physical interaction during the mixing of two solutions or of a solid or a liquid in a constant temperature environment is monitored as a function of time (120). Studies suggest that solution calorimetry can be used to determine the amorphous content of a drug and excipient, when the solubility and dissolution rate of the compound in the chosen solvent are reasonably high. Typically, $100 \%$ crystalline and $100 \%$ amorphous materials have been physically mixed to prepare samples of varying percent crystallinities, and a linear relationship between the heat of solution and the mass percent crystalline fraction present in the resulting mixture has been 

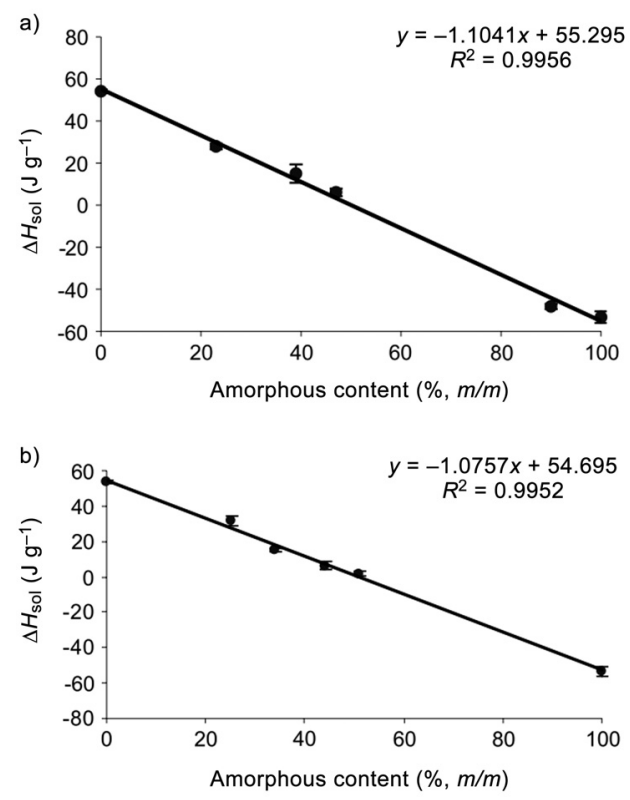

Fig. 7. Relationship between the $\Delta_{\text {sol }} H$ and the amorphous content of: a) physical mixtures; b) spray-dried samples. Mean values SD are shown $(n=4)$. Adapted from ref. 124 with permission.

demonstrated $(120,121)$. Harjunen et al. (124) have shown that this method can be also used for assessment of the amorphous content of lactose that was not completely dissolved in a solvent. An excellent correlation was observed between the enthalpy of solution $\left(\Delta_{\text {sol }} H\right)$ in water and the amorphous content of the samples, as shown in Fig. 7. Further, there was also a linear correlation between the enthalpy accompanied with addition of a lactose sample to an oversaturated aqueous solution $\left(\Delta_{\text {sat }} H\right)$ and the amorphous content of the samples, as shown in Fig. 8. Interestingly, linear relationship was observed between the $\Delta_{\text {sat }} H$ and the $\Delta_{\text {sol }} H$ of the samples. Therefore, solution calorimetry may represent a rapid and simple method for determining the amorphous content also in samples that are not completely dissolved in the solvent.

\section{Density measurements}

Solid density is a physical property, the value of which is frequently required in both fundamental and applied pharmaceutics. True density may be obtained using pycnometry, flotation density measurements, or from a single crystal structure. Flotation density measurement, however, is not suitable for powder mixtures $(125,126)$. Crystalline materials in general have higher density than their amorphous counterparts because the atoms in the crystal lattice are located at a minimum possible distance from each other. An increase in lattice disorder (decreasing crystallinity) usually results in an increase in volume and therefore a decrease in density. Changes in crystalinity should therefore be accompanied by gradual, progressive changes in density (127). The degree of 

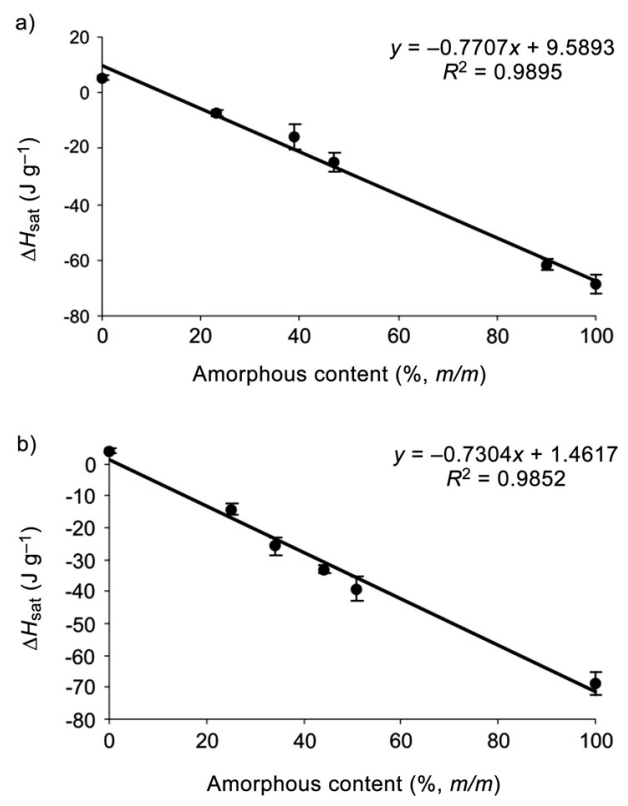

Fig. 8. Relationship between $\Delta_{\text {sat }} H$ and the amorphous content of a) physical mixtures, b) spray-dried samples. Mean values SD are shown $(n=4-8)$. Adapted from ref. 124 with permission.

crystallinity of a sample can be determined by Eq. (2) ( $\rho$ - obtained density, $\rho_{\mathrm{a}}$ - density of the fully amorphous state, $\rho_{\mathrm{c}}$ - density of the crystalline state):

$$
\text { Crystallinity }=\frac{\rho-\rho_{a}}{\rho_{c}-\rho_{a}} \times 100
$$

Different density measurement techniques were used in literature to detect low levels of the amorphous phase in crystalline pharmaceuticals (128) or to determine sample crystallinity $(1,129)$. Therefore, density measurements can be also used as an alternative technique to determine the solid state of pharmaceuticals. Salekigerhardt et al. (130) have shown that an increase in density correlates with the disorder of solid sucrose (Fig. 9).

\section{Gravimetric vapor sorption}

Gravimetric vapor sorption is a technique used to determine the vapor sorption isotherms. Instruments measure how the mass of the sample changes as the vapor environment surrounding the sample is altered. An increase in mass is typically associated with vapor sorption, whilst the occurence of mass decrease is attributed to vapor desorption. Mixed saturated and dry carrier gas streams are used to control the vapour concentration around the sample. Dynamic vapor sorption has been previously used to characterize amorphous or partially amorphous systems (131). The principle behind it is that 


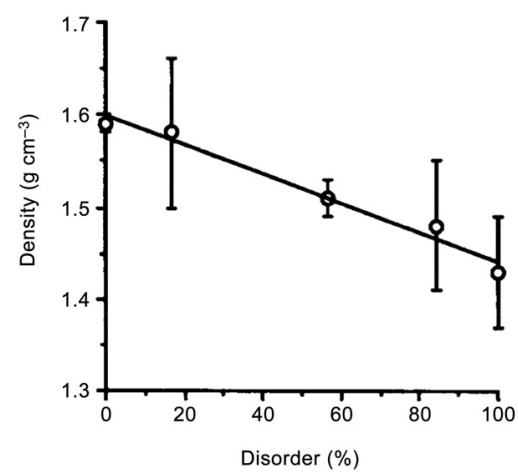

Fig. 9. Density vs. percent disorder for mixtures of amorphous and crystalline sucrose. Adapted from ref. 130 with permission.

amorphous materials typically have a higher surface area and vapour affinity than their crystalline counterparts. More recently Vollenbroek et al. (132) have developed a method which is based on gravimetric vapor sorption that allows determination of the amorphous lactose content over the range of $0.1-100 \%$. However, it must be noted that using dynamic vapor sorption for determination of amorphous content may be flawed, because direct comparison of partially amorphous particles to wholly amorphous and wholly crystalline systems may result in a significantly different outcome. This is due to the fact that semicrystalline materials have different molecular mobility compared to wholly amorphous or crystalline material (13).

\section{Inverse gas cromatography}

Inverse gas chromatography (IGC) is a vapor sorption technique in which powder is packed in a column and known vapors (usually at infinitine dilution in a carrier gas) are injected. It provides access to several physicochemical (surface and bulk) properties of materials, including their surface energy, phase transitions, solubility parameter, crystallinity, and acid-base characteristics $(133,134)$. It has been also used to detect surface energy changes caused by milling (135). It was found for sucrose that milling does not influence the crystal structure particles, but only the particle size and relative exposure of specific crystal planes. From the retention times of the probes it is possible to assess the surface nature of the material in the column (130). It is expected that this vapor sorption approach is also able to detect small amounts of amorphous content (88). Planinsek et al. (136) have shown that IGC is an efficient method for the quantification of the fraction of amorphous surface of milled indomethacin. It was shown that combination of IGC with DSC enables not only quantification but also localization of structural changes of milled indomethacin. Namely, it enables differentiation between the transformed structure at the surface of particles and transformations of the bulk region. 


\section{MID infrared spectroscopy}

Middle (MID) infrared methods can reflect significant spectral differences between crystalline and amorphous phases and are hence used to quantify the crystalline content, since the intensity of the vibrational bands is directly proportional to the concentration of the concerned phase. Amorphous form of a given drug give rise to IR spectra that differs from its crystalline counterparts. The origin of these differences relates to both the wider range of conformations typically present in an amorphous solid, which normally leads to the presence of broader peaks relative to those found in the crystalline spectrum, as well as to differences in intermolecular interactions (1). Infrared procedures for measuring the degree of crystallinity are based upon the measurement of the intensity of a peak, characteristic of the crystalline state with reference to a peak that is independent of the crystal state of the substance. Nakai et al. (75) have shown that it is possible to study the effect of grinding on the crystallinity of microcrystalline cellulose (MCC) using the infrared technique and similarly Otsuka and his coworkers (137) also studied the effect of grinding on the crystallinity of cephalothin. MID-IR has also been found to be extremely useful to study amorphous solid dispersions (138). A study by Tang et al. (139) used FT-IR spectroscopy to characterize the differences between crystalline and the amorphous phases of dihydropyridine calcium channel blockers. For all compounds, the amorphous and crystalline samples gave rise to different spectra.

\section{Near infrared spectroscopy}

Near infrared spectroscopy (NIR) is a noninvasive technique, which requires no sample preparation; it is also non-destructive, enabling complete sample retrieval especially if used with the diffuse reflectance option. In addition, further quantitative information can be extracted from the data using chemoinfometrics, where the collected data is processed by means of statistical and applied mathematical techniques. Quantification of crystallinity is usually performed using the first (140) or second derivate spectra (95, 141, 142). Physical and chemical information such as polymorphism (143) and mutarotation (144) may be obtained. Buckton et al. (145) have shown that it is possible to monitor the crystallization of amorphous lactose in real time through examination of NIR spectra at certain wavelengths. Moreover, Hogan et al. (144) have shown that it is possible to quantify the amorphous content of lactose with NIR. Luner et al. (141) used the technique to determine the crystallinity of several pharmaceuticals, including indomethacin, lactose, ampicillin and sucrose. NIR was also used by Otsuka et al. (146) to monitor the stability of amorphous indomethacin in humidity controlled 96-well plates. Furthermore, Otsuka et al. (147) have shown that the crystallinity of unknown samples obtained by FT-NIR chemoinfometrical spectrometry was consistent with that obtained by conventional X-ray powder diffractometry and was more accurate (Fig. 10). According to the change in NIR absorbance of indomethacin, the solid structure of amorphous indomethacin was significantly different from that of the crystalline form.

\section{Raman spectroscopy}

Raman spectroscopy is a spectroscopic method used to observe vibrational, rotational, and other low-frequency modes in a system. It probes properties of the molecule it- 


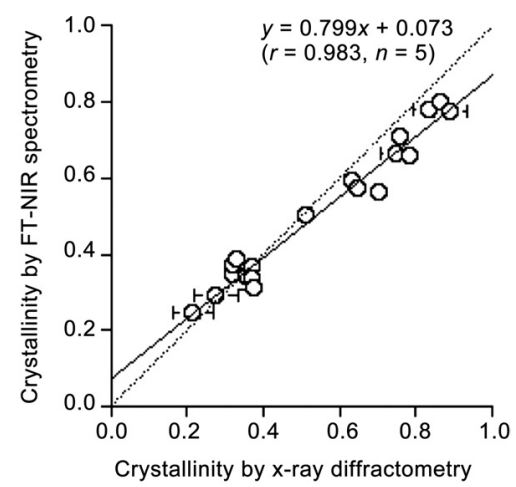

Fig. 10. Relation between predicted crystallinity of unknown indomethacin samples obtained by the conventional X-ray powder and FT-NIR method. Bars represent standard deviation. Adapted from ref. 147 with permission.

self, and changes in the solid-state properties of a substance are inferred from changes in the molecular conformation and molecular environment. This is due to the different packing conditions of the molecules in different solid forms. Differences can then be seen as subtle changes in the peak positions and intensities in the Raman spectra (148). It has been recently used in various studies for means of differentiation between differently prepared amorphous forms of the same substace. Karmwar et al. $(8,149)$ have shown that this is a suitable method for the detection of differences between differently prepared amorphous forms of indomethacin and simvastatin. Similarly Zimper et al. (79) have shown that Raman spectroscopy combined with multivariate analysis can detect and quantify disorder in a substance. Nevertheless, the authors point out that Raman spectroscopy, as a molecular level technique, is sensitive to the near order of solid materials and therefore could 'underestimate' the degree of disorder if the material remains near the range ordered to a certain extent (i.e., exists as a dimer) in the amorphous state. However, in contrast to the findings of the previous authors, Boetker et al. (150) have found that it is unable to distinguish between differently prepared samples of amlopidine.

\section{Dissolution tests}

As the molecular mobility of the amorphous form is higher compared to the equivalent crystalline form, it may have an enhanced dissolution rate. This difference can be used to estimate the degree of amorphous content in a given sample. Although the amorphous form will have a higher dissolution rate because of high-surface free energy, there is an inherent risk of devitrification in the dissolution fluid (151), rendering dissolution tests useless for characterization of the solid state. However, the amount dissolved has been used to quantify crystallinity in the case of amorphous solid dispersions. (152). The main problem encountered in this technique is the effect of surface area; if not controlled stringently, it can significantly affect the results. To control the surface area, the powder is compressed. This may lead to probable phase changes. Also, the dissolution medium needs to be carefully selected as the components of the medium can influ- 
a)

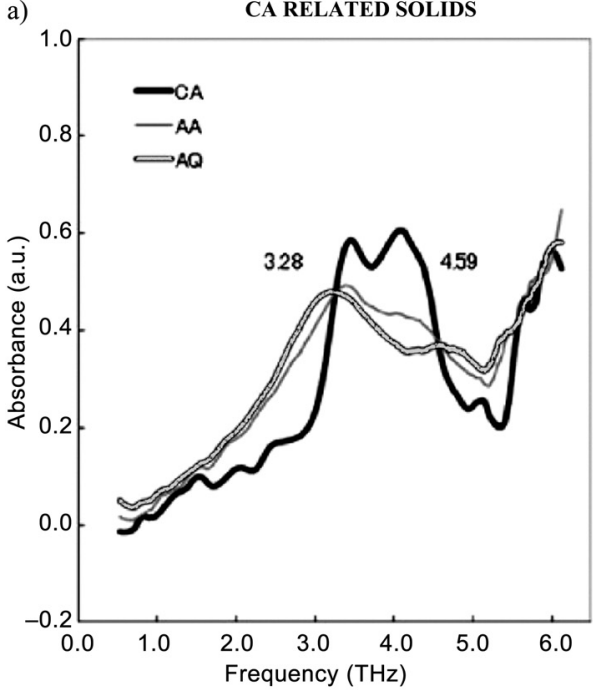

b)

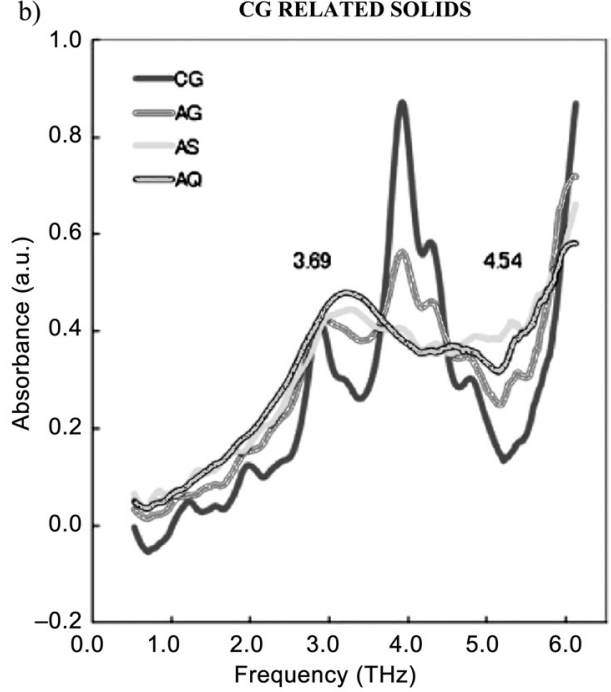

Fig. 11. Terahertz spectra of amorphous samples derived from $\alpha$ - and $\gamma$-indomethacin forms using different preparation techniques: a) powder samples prepared from $\alpha$-indomethacin; b) powder samples prepared form $\gamma$-indomethacin. CA $\alpha$-indomethacin, CG $-\gamma$-indomethacin, AA - ground amorphous $\alpha$-indomethacin, AQ - fast cooled amorphous indomethacin, AG - ground amorphous $\gamma$-indomethacin, AS - slowly cooled indomethacin. Adapted from ref. (9) with permission.

ence the final outcome (88). Care must be taken when using this method if the transformation process includes extensive crystal defect formation, which is especially expected in the early stages of amorphization due to mechanical milling. Because the dissolution depends on solvent accessible surface and surface energy, crystal defect formation and increased surface could lead to false results.

\section{Microcalorimetry}

Microcalorimetry is a technique that has attracted much interest among pharmaceutical researchers as it can be used for various studies of preformulation. One among the possible uses of microcalorimetry is also assessment of the amorphous content (153156). Determination of the amorphous content by microcalorimetry is based on the fact that conversion from the amorphous to the crystalline form is detected as an exothermic heat flow. The area under the exothermic peak is then proportional to the amorphous content. In some cases, the sensitivity of the calorimetric approach was even proven to be better than XRPD. Furthermore, one of the advantages of the technique is that it allows to measure the »real time" response in the calorimeter monitoring recrystallization of the amorphous substance (154). 


\section{Terahertz spectroscopy}

Detection of terahertz radiation waves $(\mathrm{THz})$, which have a frequency between 0.1 and $10 \mathrm{THz}$, is potentially very useful in probing intermolecular-level long range without sample contact and destructive treatment when characterizing solid-state materials, since it can induce low frequency bond vibrations, crystalline phonon vibrations hydrogen-bonding stretches, and torsion vibrations (153). A recent study by Otsuka et al. (9) has shown that $\mathrm{THz}$ spectroscopy is suited as a discrimination method between different amorphous states of pharmaceuticals called "poly-amorphous solids«. Fig. 11 shows the $\mathrm{THz}$ spectra of polymorphic crystalline forms and the amorphous solids of indomethacin obtained by the transmittance method.

\section{CONCLUSIONS}

Due to their higher solubility and bioavailability compared to the crystalline state, amorphous solids have received a lot of attention in the past decades. In this review, we have presented the possible methods of preparation of amorphous solids and their characterization. We elaborated on the background mechanisms involved in the process of amorphization, with the emphasis on amorphization through milling. The wide array of solid-state characterization techniques that can be utilized to investigate the different properties of the amorphous forms of substances prepared by various methods is also presented, since amorphous forms prepared by different means of amorphization often exhibit differences in stability and solubility. Moreover, differences can be also screened by commonly used methods of solid state characterization. We concluded that a multivariate visualization combined with complementing spectroscopic characterization offers an effective tool to screen for differences in amorphous samples.

\section{REFERENCES}

1. B. C. Hancock and G. Zografi, Characteristics and significance of the amorphous state in pharmaceutical systems, J. Pharm. Sci. 86 (1997) 1-12; DOI: 10.1021/js9601896.

2. L. Yu, Amorphous pharmaceutical solids: preparation, characterization and stabilization, Adv. Drug Delivery Rev. 48 (2001) 27-42; DOI: 10.1016/S0169-409X(01)00098-9.

3. G. L. Amidon, H. Lennernäs, V. P. Shah and J. R. Crison, A theoretical basis for a biopharmaceutic drug classification: the correlation of in vitro drug product dissolution and in vivo bioavailability, Pharm. Res. 12 (1995) 413-420; DOI: 10.1023/A:1016212804288.

4. P. Poole, T. Grande, C. Angell and P. McMillan, Polymorphic phase transitions in liquids and glasses, Science 275 (1997) 322-323; DOI: 10.1126/science.275.5298.322.

5. A. Saleki-Gerhardt, J. G. Stowell, S. R. Byrn and G. Zografi, Hydration and dehydration of crystalline and amorphous forms of raffinose, J. Pharm. 84 (1995) 318-323.

6. L. R. L. Hilden and K. R. K. Morris, Physics of amorphous solids, J. Pharm. 93 (2003) 3-12; DOI: 10.1002/jps.10489.

7. K. A. Graeser, C. J. Strachan, J. E. Patterson, K. C. Gordon and T. Rades, Physicochemical properties and stability of two differently prepared amorphous forms of simvastatin, Cryst. Growth Des. 8 (2008) 128-135; DOI: 10.1021/cg700913m. 
8. P. Karmwar, K. Graeser, K. C. Gordon, C. J. Strachan and T. Rades, Investigation of properties and recrystallisation behaviour of amorphous indomethacin samples prepared by different methods, Int. J. Pharm. 417 (2011) 94-100; DOI: 10.1016/j.ijpharm.2010.12.019.

9. M. Otsuka, J.-I. Nishizawa, N. Fukura and T. Sasaki, Characterization of poly-amorphous indomethacin by terahertz spectroscopy, J. Infrared Milli. Terahz. Waves 33 (2012) 953-962; DOI: 10. 1007/s10762-012-9910-1.

10. R. Lefort, A. De Gusseme, J. F. Willart, F. Danède and M. Descamps, Solid state NMR and DSC methods for quantifying the amorphous content in solid dosage forms: an application to ball-milling of trehalose, Int. J. Pharm. 280 (2004) 209-219; DOI: 10.1016/j.ijpharm.2004.05.012.

11. D. Kivelson, J. Pereda, K. Luu, M. Lee, H. Sakai, A. Ha, I. Cohen and G. Tarjus, Facts and speculation concerning low-temperature polymorphism in glass formers, Symp. Ser. 676 (1997), 224232; DOI: 10.1021/bk-1997-0676.ch017.

12. J. E. Patterson, M. B. James, A. H. Forster, R. W. Lancaster, J. M. Butler and T. Rades, The influence of thermal and mechanical preparative techniques on the amorphous state of four poorly soluble compounds, J. Pharm. Sci. 94 (2005) 1998-2012; DOI: 10.1002/jps.20424.

13. D. Q. D. Craig, V. L. V. Kett, J. R. J. Murphy and D. M. D. Price, The measurement of small quantities of amorphous material-should we be considering the rigid amorphous fraction, Pharm. Res. 18 (2001) 1081-1082.

14. D. Turnbull, Under what conditions can a glass be formed?, Contemp. Phys. 10 (1969) 473-488; DOI: $10.1080 / 00107516908204405$.

15. C. Angell, Structural instability and relaxation in liquid and glassy phases near the fragile liquid limit, J. Non-Cryst. Solids 102 (1988) 205-221; DOI: 10.1016/0022-3093(88)90133-0.

16. J. Liu, D. Rigsbee, C. Stotz and M. Pikal, Dynamics of pharmaceutical amorphous solids: The study of enthalpy relaxation by isothermal microcalorimetry, J. Pharm. Sci. 91 (2002) 1853-1862; DOI:10.1002/jps.10181.

17. D. Grant, Polymorphism in Pharmaceutical Solids, Marcel Dekker, Basel 1999, pp. 183-227.

18. K. A. Graeser, J. E. Patterson, J. A. Zeitler, K. C. Gordon and T. Rades, Correlating thermodynamic and kinetic parameters with amorphous stability, Eur. J. Pharm. Sci. 37 (2009) 492-498; DOI: $10.1016 /$ j.ejps.2009.04.005.

19. J. W. Lee, L. C. Thomas and S. J. Schmidt, Effects of heating conditions on the glass transition parameters of amorphous sucrose produced by melt-quenching, J. Agric. Food Chem. 59 (2011) 3311-3319; DOI: $10.1021 /$ jf104853s.

20. H. Miyanishi, T. Nemoto, M. Mizuno, H. Mimura, S. Kitamura, Y. Iwao, S. Noguchi and S. Itai, Evaluation of crystallization behavior on the surface of nifedipine solid dispersion powder using inverse gas chromatography, Pharm. Res. 30 (2013) 502-511; DOI: 10.1007/s11095-012-0896-0.

21. M. G. Abiad, D. C. Gonzalez, B. Mert, O. H. Campanella and M. T. Carvajal, A novel method to measure the glass and melting transitions of pharmaceutical powders, Int. J. Pharm. 396 (2010) 23-29; DOI: 10.1016/j.ijpharm.2010.06.001.

22. H. Takeuchi, S. Nagira, H. Yamamoto and Y. Kawashima, Solid dispersion particles of tolbutamide prepared with fine silica particles by the spray-drying method, Powder Technol. 141 (2004) 187-195; DOI: 10.1016/j,powtec.2004.03.007.

23. R. C. Rowe, P. J. Sheskey, W. G. Cook and M. F. Fenton, Colloidal Silicon Dioxide, in Handbook of Pharmaceutical Excipients, Pharmaceutical Press, London 2000, pp. 143-145.

24. H. Takeuchi, T. Handa and Y. Kawashima, Spherical solid dispersion containing amorphous tolbutamide embedded in enteric coating polymers or colloidal silica prepared by spray-drying technique, Chem. Pharm. Bull. 35 (1987) 3800-3806.

25. I. Chuang and G. Maciel, Probing hydrogen bonding and the local environment of silanols on silica surfaces via nuclear spin cross polarization dynamics, J. Am. Chem. Soc. 118 (1996) 401406; DOI: $10.1021 /$ ja951550d. 
26. J. Broadhead, S. K. E. Rouan and C. T. Rhodes, The spray drying of pharmaceuticals, Drug. Dev. Ind. Pharm. 18 (1992) 11-12; DOI: 10.3109/03639049209046327.

27. R. Vehring, Pharmaceutical particle engineering via spray drying, Pharm. Res. 25 (2008) 9991022; DOI: $10.1007 /$ s11095-007-9475-1.

28. K. Haque and Y. H. Roos, Crystallization and X-ray diffraction of spray-dried and freeze-dried amorphous lactose, Carbohyd. Res. 340 (2005) 293-301; DOI: 10.1016/j.carres.2004.11.026.

29. D. Chiou, T. A. G. Langrish and R. Braham, The effect of temperature on the crystallinity of lactose powders produced by spray drying, J. Food Eng. 86 288-293; DOI: 10.1016/j.jfoodeng.2007. 10.005.

30. S. P. Bhardwaj, K. K. Arora, E. Kwong, A. Templeton, S. D. Clas and R. Suryanarayanan, Correlation between molecular mobility and physical stability of amorphous itraconazole, Mol. Pharm. 10 (2013) 694-700; DOI: 10.1021/mp300487u.

31. M. Vogt, K. Kunath and J. B. Dressman, Dissolution enhancement of fenofibrate by micronization, cogrinding and spray-drying: comparison with commercial preparations, Eur. J. Pharm. Biopharm. 68 (2008) 283-288; DOI: 10.1016/j.ejpb.2007.05.010.

32. D. Q. Craig, P. G. Royall, V. L. Kett and M. L. Hopton, The relevance of the amorphous state to pharmaceutical dosage forms: glassy drugs and freeze dried systems, Int. J. Pharm. 179 (1999) 179-207; DOI: 10.1016/S0378-5173(98)00338-X.

33. J. Liu, Physical characterization of pharmaceutical formulations in frozen and freeze-dried solid states: techniques and applications in freeze-drying development, Pharm. Dev. Technol. 11 (2006) 3-28; DOI: 10.1080/10837450500463729.

34. S. P. Bhardwaj and R. Suryanarayanan, Molecular mobility as an effective predictor of the physical stability of amorphous trehalose, Mol. Pharm. 9 (2012) 3209-3217; DOI: 10.1021/mp300302g.

35. K. P. O'Donnell, Z. Cai, P. Schmerler and R. O. I. Williams, Atmospheric freeze drying for the reduction of powder electrostatics of amorphous, low density, high surface area pharmaceutical powders, Drug Dev. Ind. Pharm. 39 (2013) 205-217; DOI: 10.3109/03639045.2012.669385.

36. Y. Li, J. Han, G. G. Zhang, D. J. Grant and R. Suryanarayanan, In situ dehydration of carbamazepine dihydrate: a novel technique to prepare amorphous anhydrous carbamazepine, Pharm. Dev. Technol. 5 (2000) 257-266; DOI: 10.1081/PDT-100100540.

37. F. Sussich and A. Cesaro, Trehalose amorphization and recrystallization, Carboh. Res. 343 26672674; DOI: 10.1016/j.carres.2008.08.008.

38. B. Bennett and G. Cole, Secondary Pharmaceutical Production: An Engineering Guide, IChemE 2003, pp. 111-201.

39. D. M. Parikh, Handbook of Pharmaceutical Granuation Technology, Taylor and Francis, London 2005, pp. 491-512.

40. R. Liu, Water-InsolubleDrug Formulation, Taylor and Francis, London 2008, pp. 88-455.

41. R. Price and P. M. Young, On the physical transformations of processed pharmaceutical solids, Micron. 36 (2005) 519-524; DOI: 10.1016/j.micron.2005.04.003.

42. G. Zhang, C. Gu, M. Zell, R. Burkhardt, E. Munson and D. Grant, Crystallization and transitions of sulfamerazine polymorphs, J. Pharm. Sci. 91 (2002) 1089-1100; DOI: 10.1002/jps.10100.

43. P. Thanatuksorn, K. Kawai, K. Kajiwara and T. Suzuki, Effects of ball-milling on the glass transition of wheat flour constituents, J. Sci. Food Agric. 89 (2009) 430-435; DOI: 10.1002/jsfa.3463.

44. J. F. Willart and M. Descamps, Solid state amorphization of pharmaceuticals, Mol. Pharmaceutics 5 (2008) 905-920; DOI: 10.1021/mp800092t.

45. A. Revesz, Melting behavior and origin of strain in ball-milled nanocrystalline Al powders, J. Mater. Sci. 40 (2005) 1643-1646; DOI: 10.1007/s10853-005-0664-1.

46. S. Karki, T. Friscic, W. Jones and W. D. S. Motherwell, Screening for pharmaceutical cocrystal hydrates via neat and liquid-assisted grinding, Mol. Pharmaceutics 4 (2007) 347-354; DOI: 10. $1021 / \mathrm{mp} 0700054$. 
47. K. Chadwick, R. Davey and W. Cross, How does grinding produce co-crystals? Insights from the case of benzophenone and diphenylamine, CrystEngComm 9 (2007) 732-734; DOI: 10.1039/ b709411f.

48. T. Shakhtshneider, Phase transformations and stabilization of metastable states of molecular crystals under mechanical activation, Solid State Ionics 101 (1997) 851-856; DOI: 10.1016/S01672738(97)00224-5.

49. E. Dudognon, J. Willart, V. Caron, F. Capet, T. Larsson and M. Descamps, Formation of budesonide/alpha-lactose glass solutions by ball-milling, Solid State Commun. 138 (2006) 68-71; DOI: 10.1016/j.ssc.2006.02.007.

50. I. Tsukushi, O. Yamamuro and T. Matsuo, Solid state amorphization of organic molecular crystals using a vibrating mill, Solid State Commun. 94 (1995) 1013-1013; DOI: 10.1016/0038-1098 (95)00161-1.

51. J. Font, J. Muntasell and E. Cesari, Amorphization of organic compounds by ball milling, Mater. Res. Bull. 32 (1997) 1691-1696; DOI: 10.1016/S0025-5408(97)00162-1.

52. J. Willart, V. Caron, R. Lefort, F. Danède, D. Prevost and M. Descamps, Athermal character of the solid state amorphization of lactose induced by ball milling, Solid State Commun. 132 (2004) 693-696; DOI: 10.1016/j.ssc.2004.09.007.

53. M. Otsuka, H. Ohtani, N. Kaneniwa and S. Higuchi, Isomerization of lactose in solid-state by mechanical stress during grinding, J. Pharm. Pharmacol. 43 (1991) 148-153; DOI: 10.1111/j.20427158.1991.tb06656.x.

54. J. Willart, A. De Gusseme, S. Hemon, G. Odou, F. Danède and M. Descamps, Direct crystal to glass transformation of trehalose induced by ball milling, Solid State Commun. 119 (2001) 501505; DOI: 10.1016/S0038-1098(01)00283-6.

55. A. J. Megarry, J. Booth and J. Burley, Amorphous trehalose dihydrate by cryogenic milling, Carbohyd. Res. 346 (2011) 1061-1064; DOI: 10.1016/j.carres.2011.03.011.

56. J. F. Willart, N. Dujardin, E. Dudognon, F. Danède and M. Descamps, Amorphization of sugar hydrates upon milling, Carbohyd. Res. 345 (2010) 1613-1616; DOI: 10.1016/j.carres.2010.04.014.

57. P. Okamoto and N. Lam, Physics of crystal-to-glass transformations, Solid State Phys. 52 (1999) 1-135; DOI: 10.1016/S0081-1947(08)60018-1.

58. H. Fecht, Defect-induced melting and solid-state amorphization, Nature 356 (1992) 133-135; DOI: 10.1016/S0081-1947(08)60018-1.

59. M. Descamps, J. F. Willart, E. Dudognon and V. Caron, Transformation of pharmaceutical compounds upon milling and comilling: the role of $T_{g^{\prime}}$ J. Pharm. Sci. 96 (2007) 1398-1407; DOI: 10. 1002/jps.20939.

60. J. Willart, N. Descamps, V. Caron, F. Capet, F. Danède and M. Descamps, Formation of lactose-mannitol molecular alloys by solid state vitrification, Solid State Commun. 138 (2006) 194-199; DOI: $10.1016 /$ j.ssc.2006.02.034.

61. G. Martin and P. Bellon, Driven alloys, Solid State Phys. 50 (1997) 189-331.

62. S. Qi, I. Weuts, S. De Cort, S. Stokbroekx, R. Leemans, M. Reading, P. Belton and D. Q. M. Craig, An investigation into the crystallisation behaviour of an amorphous cryomilled pharmaceutical material above and below the glass transition temperature, J. Pharm. Sci. 99 (2010) 196-208; DOI: $10.1002 /$ jps.21811.

63. K. J. Crowley and G. Zografi, Cryogenic grinding of indomethacin polymorphs and solvates: assessment of amorphous phase formation and amorphous phase physical stability, J. Pharm. Sci. 91 (2002) 492-507; DOI: 10.1002/jps.10028.

64. J. Carstensen, Advanced Pharmaceutical Solids, Marcel Dekker, New York 2001, pp. 107-117.

65. C. Sun and D. J. Grant, Influence of crystal shape on the tableting performance of L-lysine monohydrochloride dihydrate, J. Pharm. Sci. 90 (2001) 569-579; DOI: 10.1002/1520-6017(200105)90: 5<569::AID-JPS1013>3.0.CO;2-4. 
66. V. Chikhalia, R. T. Forbes, R. A. Storey and M. Ticehurst, The effect of crystal morphology and mill type on milling induced crystal disorder, Eur. J. Pharm. Sci. 27 (2006) 19-26; DOI: 10.1016/ j.ejps.2005.08.013.

67. T. Watanabe, S. Hasegawa, N. Wakiyama, A. Kusai and M. Senna, Comparison between polyvinylpyrrolidone and silica nanoparticles as carriers for indomethacin in a solid state dispersion, Int. J. Pharm. 250 (2003) 283-286; DOI: 10.1016/S0378-5173(02)00549-5.

68. A. Ali, K. Yamamoto, A. Elsayed, F. Habib and Y. Nakai, Molecular behavior of flufenamic acid in physical and ground mixtures with florite, Chem. Pharm. Bull. 40 (1992) 1289-1294.

69. H. Sekizaki, K. Danjo, H. Eguchi, Y. Yonezawa, H. Sunada and A. Otsuka, Solid-state interaction of ibuprofen with polyvinylpyrrolidone, Chem. Pharm. Bull. 43 (1995) 988-993.

70. V. Boldyrev, T. Shakhtshneider, L. Burleva and V. Severstev, Preparation of the disperse systems of sulfathiazole-polyvinylpyrrolidone by mechanical activation, Drug Dev. Ind. Pharm. 20 (1994) 1103-1114.

71. N. Kaneniwa and A. Ikekava, Solubilization of Water-insoluble organic powders by ball-milling in the presence of polyvinylpyrrolidone, Chem. Pharm. Bull. 23 (1975) 2973-2986.

72. N. Kaneniwa, A. Ikekava and M. Sumi, A decrease in crystallinity of amobarbital by mechanical treatment in presence of diluents, Chem. Pharm. Bull. 26 (1978) 2734-2743.

73. H. Takeuchi, S. Nagira, H. Yamamoto and Y. Kawashima, Solid dispersion particles of amorphous indomethacin with fine porous silica particles by using spray-drying method, Int. J. Pharm. 293 (2005) 155-164; DOI: 10.1016/j.ijpharm.2004.12.019.

74. M. Fujii, H. Okada, Y. Shibata, H. Teramachi, M. Kondoh and Y. Watanabe, Preparation, characterization, and tableting of a solid dispersion of indomethacin with crospovidone, Int. J. Pharm. 293 (2005) 145-153; DOI: 10.1016/j.ijpharm.2004.12.018.

75. Y. Nakai, E. Fukuoka, S. Nakajima and Y. Iida, Effect of grinding on physical and chemical properties of crystalline medicinals with microcrystalline cellulose. 2. Retention of volatile medicinals in ground mixture, Chem. Pharm. Bull. 26 (1978) 2983-2989.

76. M. Cirri, F. Maestrelli, S. Furlanetto and P. Mura, Solid-state characterization of glyburide-cyclodextrin co-ground products, J. Therm. Anal. Calorim. 77 (2004) 413-422; DOI: 10.1023/B: JTAN.0000038982.40315.8f.

77. T. Shakhtshneider, M. Vasiltchenko, A. Politov and V. Boldyrev, The mechanochemical preparation of solid disperse systems of ibuprofen-polyethylene glycol, Int. J. Pharm. 130 (1996) 25-32; DOI: 10.1016/0378-5173(95)04244-X.

78. D. Bahl and R. H. Bogner, Amorphization of indomethacin by co-grinding with Neusilin US2: Amorphization kinetics, physical stability and mechanism, Pharm. Res. 23 (2006) 2317-2325; DOI: $10.1007 /$ s11095-006-9062-x.

79. U. Zimper, J. Aaltonen, C. M. McGoverin, K. C. Gordon, K. Krauel-Goellner and T. Rades, Quantification of process induced disorder in milled samples using different analytical techniques, Pharmaceutics 2 (2010) 30-49; DOI: 10.3390/pharmaceutics2010030.

80. V. Caron, J. F. Willart, R. Lefort, P. Derollez, F. Danède and M. Descamps, Solid state amorphization kinetic of alpha lactose upon mechanical milling, Carbohyd. Res. 346 (2011) 2622-2628; DOI: 10.1016/j.carres.2011.09.004.

81. J. P. Bøtker, P. Karmwar, C. J. Strachan, C. Cornett, F. Tian, Z. Zujovic, J. Rantanen and T. Rades, Assessment of crystalline disorder in cryo-milled samples of indomethacin using atomic pair-wise distribution functions, Int. J. Pharm. 417 (2011) 112-119; DOI: 10.1016/j.ijpharm.2010.12. 018.

82. K. Terada, H. Kitano, Y. Yoshihashi and E. Yonemochi, Quantitative correlation between initial dissolution rate and heat of solution of drug, Pharm. Res. 17 (2000) 920-924; DOI: 10.1023/A: 1007514902161. 
83. Z. Lavrič, J. Pirnat, J. Lužnik, J. Seliger, V. Žagar, Z. Trontelj and S. Srcic, Application of $14 \mathrm{~N}$ NQR to the study of piroxicam polymorphism, J. Pharm. Sci. 99 (2010) 4857-4865; DOI: 10.1002/ jps.22186.

84. C. J. Strachan, T. Rades and K. C. Gordon, A theoretical and spectroscopic study of gamma-crystalline and amorphous indomethacin, J. Pharm. Pharmacol. 59 (2007) 261-269; DOI: 10.1211/ jpp.59.2.0012.

85. M. Savolainen, A. Heinz, C. Strachan, K. C. Gordon, J. Yliruusi, T. Rades and N. Sandler, Screening for differences in the amorphous state of indomethacin using multivariate visualization, Eur. J. Pharm. Sci. 30 (2007) 113-123; DOI: 10.1016/j.ejps.2006.10.010.

86. C. Rawle, C. Lee, C. Strachan, K. Payne, P. Manson and T. Rades, Towards characterization and identification of solid state pharmaceutical mixtures through second harmonic generation, J. Pharm. Sci. 95 (2006) 761-768; DOI: 10.1002/jps.20575.

87. G. G. Buckton and P. P. Darcy, Assessment of disorder in crystalline powders - a review of analytical techniques and their application, Int. J. Pharm. 179 (1999) 141-158; DOI: 10.1016/S03785173(98)00335-4.

88. B. Shah, V. K. Kakumanu and A. K. Bansal, Analytical techniques for quantification of amorphous/crystalline phases in pharmaceutical solids, J. Pharm. Sci. 95 (2006) 1641-1665; DOI: 10. 1002 /jps.20644.

89. N. Chieng, Z. Zujovic, G. Bowmaker, T. Rades and D. Saville, Effect of milling conditions on the solid-state conversion of ranitidine hydrochloride form 1, Int. J. Pharm. 327 (2006) 36-44; DOI: 10.1016/j.ijpharm.2006.07.032.

90. C. Gustafsson, H. Lennholm, T. Iversen and C. Nyström, Comparison of solid-state NMR and isothermal microcalorimetry in the assessment of the amorphous component of lactose, Int. J. Pharm. 174 (1998) 243-252; DOI: 10.1016/S0378-5173(98)00272-5.

91. M. Mirmehrabi, S. Rohani, K. S. K. Murthy and B. Radatus, Characterization of tautomeric forms of ranitidine hydrochloride: thermal analysis, solid-state NMR, X-ray, J. Cryst. Growth 260 (2004) 517-526; DOI: 10.1016/j.jcrysgro.2003.08.061.

92. D. C. Apperley, R. A. Fletton, R. K. Harris, R. W. Lancaster, S. Tavener and T. L. Threlfall, Sulfathiazole polymorphism studied by magic-angle spinning NMR, J. Pharm. Sci. 88 (1999) 12751280; DOI: 10.1021/js990175a.

93. D. C. Apperley, R. K. Harris, T. Larsson and T. Malmstrom, Quantitative nuclear magnetic resonance analysis of solid formoterol fumarate and its dihydrate, J. Pharm. Sci. 92 (2003) 2487-2494; DOI: $10.1002 /$ jps.10500.

94. P. A. Tishmack, D. E. Bugay and S. R. Byrn, Solid-state nuclear magnetic resonance spectroscopy-pharmaceutical applications, J. Pharm. Sci. 92 (2003) 441-474; DOI: 10.1002/jps.10307.

95. A. Gombás, I. Antal, P. Szabó-Révész, S. Marton and I. Erõs, Quantitative determination of crystallinity of alpha-lactose monohydrate by near Infrared Spectroscopy (NIRS), Int. J. Pharm. 256 (2003) 25-32; DOI: 10.1016/S0378-5173(03)00059-0.

96. P. Debenedetti, Metastable Liquids: Concepts and Principles, Princeton University Press, Chichester 1996.

97. G. P. Johari, S. Ram, G. Astl and E. Mayer, Characterizing amorphous and microcrystalline solids by calorimetry, J. Non-Cryst Solids 116 (1990) 282-285; DOI: 10.1016/0022-3093(90)90703-O.

98. S. Bates, G. Zografi, D. Engers, K. Morris, K. Crowley and A. Newman, Analysis of amorphous and nanocrystalline solids from their X-ray diffraction patterns, Pharm. Res. 23 (2006) 23332349; DOI: 10.1007/s11095-006-9086-2.

99. S. J. L. Billinge and M. G. Kanatzidis, Beyond crystallography: the study of disorder, nanocrystallinity and crystallographically challenged materials with pair distribution functions, Chem. Commun. 7 (2004) 749-760; DOI: 10.1039/b309577k. 
100. A. S. Masadeh, E. S. Bozin, C. L. Farrow, G. Paglia, P. Juhas, S. J. L. Billinge, A. Karkamkar and M. G. Kanatzidis, Quantitative size-dependent structure and strain determination of CdSe nanoparticles using atomic pair distribution function analysis, Phys. Rev. B 76 (2007); DOI: 10. 1103/PhysRevB.76.115413.

101. T. Egami and S. J. L. Billinge, Underneath the Bragg Peaks, Pergamon Press, Oxford 2003, pp. 25-101.

102. T. Proffen, S. Billinge, T. Egami and D. Louca, Structural analysis of complex materials using the atomic pair distribution function - a practical guide, Z. Kristallogr. 218 (2003) 132-143; DOI: 10.1524/zkri.218.2.132.20664.

103. L. Tarasov and B. E. Warren, X-ray diffraction study of liquid sodium, J. Chem. Phys. 4 (1936) 236-238; DOI: 10.1063/1.1749828.

104. B. Warren, H. Krutter and O. Morningstar, Fourier-analysis of X-ray-patterns of vitreous $\mathrm{SiO}_{2}$ and $\mathrm{B}_{2} \mathrm{O}_{3}$, J. Am. Ceram. Soc. 75 (1992) 11-15.

105. F. Zernike and J. A. Prins, Die Beugung von Röntgenstrahlen in Flüssigkeiten als Effekt der Molekülanordnung, Z. Physik 41 (1927) 184-194; DOI: 10.1007/BF01391926.

106. F. Atassi, C. Mao, A. S. Masadeh and S. R. Byrn, Solid-state characterization of amorphous and mesomorphous calcium ketoprofen, J. Pharm. Sci. 99 (2009) 3684-3697; DOI: 10.1002/jps.21925.

107. S. Bates, R. C. Kelly, I. Ivanisevic, P. Schields, G. Zografi and A. W. Newman, Assessment of defects and amorphous structure produced in raffinose pentahydrate upon dehydration, J. Pharm. Sci. 96 (2007) 1418-1433; DOI: 10.1002/jps.20944.

108. A. Heinz, C. J. Strachan, F. Atassi, K. C. Gordon and T. Rades, Characterizing an amorphous system exhibiting trace crystallinity: A case study with saquinavir, Crys. Growth Des. 8 (2008) 119-127; DOI: 10.1021/cg700912q.

109. A. Sheth, S. Bates, F. Muller and D. Grant, Polymorphism in piroxicam, Cryst. Growth Des. 4 (2004) 1091-1098; DOI: 10.1021/cg049876y.

110. A. Sheth, S. Bates, F. Muller and D. Grant, Local structure in amorphous phases of piroxicam from powder X-ray diffractometry, Cryst. Growth Des. 5 (2005) 571-578; DOI: 10.1021/cg049757i.

111. M. D. Moore, A. M. Steinbach, I. S. Buckner and P. L. Wildfong, A structural investigation into the compaction behavior of pharmaceutical composites using powder X-ray diffraction and total scattering analysis, Pharm. Res. 26 (2009) 2429-2437; DOI: 10.1007/s11095-009-9954-7.

112. A. Newman, D. Engers, S. Bates, I. Ivanisevic, R. C. Kelly and G. Zografi, Characterization of amorphous API: Polymer mixtures using X-ray powder diffraction, J. Pharm. Sci. 97 (2008) 4840-4856; DOI: $10.1002 / j p s .21352$.

113. K. Nollenberger, A. Gryczke, C. Meier, J. Dressman, M. U. Schmidt and S. Brühne, Pair distribution function X-ray analysis explains dissolution characteristics of felodipine melt extrusion products, J. Pharm. Sci. 98 (2009) 1476-1486; DOI: 10.1002/jps.21534.

114. P. Robinson, HyperDSC, Speed DSC Technique, ESTAC8 Abstract Book, Barcelona (August 25-29, 2002), p. 101.

115. Y. Roos, Melting and glass transitions of low molecular weight carbohydrates, Carbohyd. Res. 238 (1993) 39-48; DOI: 10.1016/0008-6215(93)87004-C.

116. M. Brown, Introduction to Thermal Analysis: Techniques and Applications, Kluwer Academic Publishers, Amsterdam 2001.

117. Perkin Elmer, Thermal Analysis Newsletter, Application Example PETAN-51, Norwalk 2000.

118. P. Claudy, M. Siniti and J. El Hajri, Thermodynamic study of the glass relaxation phenomena DSC study of annealing of maltitol glass, J. Therm. Anal. Calorim. 68 (2002) 251-264.

119. M. J. Pikal, A. L. Lukes, J. E. Lang and K. Gaines, Quantitative crystallinity determinations for $\beta$-lactam antibiotics by solution calorimetry: Correlations with stability, J. Pharm. Sci. 67 (1978) 767-773; DOI: 10.1002/jps.2600670609. 
120. D. Gao and J. Rytting, Use of solution calorimetry to determine the extent of crystallinity of drugs and excipients, Int. J. Pharm. 151 (1997) 183-192; DOI: 10.1016/S0378-5173(97)04895-3.

121. S. E. Hogan and G. Buckton, The quantification of small degrees of disorder in lactose using solution calorimetry, Int. J. Pharm. 207 (2000) 57-64; DOI: 10.1016/S0378-5173(00)00527-5.

122. K. C. Thompson, J. P. Draper, M. J. Kaufman and G. S. Brenner, Characterization of the crystallinity of drugs: B02669, a case study, Pharm. Res. 11 (1994) 1362-1365; DOI: 10.1023/A:101 8919201058.

123. G. H. Ward and R. K. Schultz, Process-induced crystallinity changes in albuterol sulfate and its effect on powder physical stability, Pharm. Res. 12 (1995) 773-779; DOI: 10.1023/A:1016232230 638.

124. P. Harjunen, V. P. Lehto, M. Koivisto, E. Levonen, P. Paronen and K. Järvinen, Determination of amorphous content of lactose samples by solution calorimetry, Drug Dev. Ind. Pharm. 30 (2004) 809-815; DOI: 10.1081/DDC-200030302.

125. R. W. Douglas and G. A. Jones, An apparatus for the determination of small changes in density, J. Sci. Instrum. 24 (1947) 72; DOI: 10.1088/0950-7671/24/3/304.

126. J. Pelsmaekers and S. Amelinckx, Simple apparatus for comparative density measurements, Rev. Sci. Instr. 32 (1961) 828-830; DOI: 10.1063/1.1717522.

127. R. Suryanarayanan, Evaluation of two concepts of crystallinity using calcium gluceptate as a model compound, Int. J. Pharm. 24 (1985) 1-17; DOI: 10.1016/0378-5173(85)90140-1.

128. G. M. Venkatesh, M. E. Barnett, C. Owusu-Fordjour and M. Galop, Detection of low levels of the amorphous phase in crystalline pharmaceutical materials by thermally stimulated current spectrometry, Pharm. Res. 18 (2001) 98-103, DOI: 10.1023/A:1011087012826.

129. R. Huttenrauch, Molecular galenics as the basis of modern drug formation, Acta Pharm. Technol. (Suppl.) 6 (1978) 55-127.

130. A. Salekigerhardt, C. Ahlneck and G. Zografi, Assessment of disorder in crystalline solids, Int. J. Pharm. 101 (1994) 237-247; DOI: 10.1016/0378-5173(94)90219-4.

131. P. M. Young, H. Chiou, T. Tee, D. Traini, H.-K. Chan, F. Thielmann and D. Burnett, The use of organic vapor sorption to determine low levels of amorphous content in processed pharmaceutical powders, Drug Dev. Ind. Pharm. 33 (2007) 91-97; DOI: 10.1080/03639040600969991.

132. J. Vollenbroek, G. A. Hebbink, S. Ziffels and H. Steckel, Determination of low levels of amorphous content in inhalation grade lactose by moisture sorption isotherms, Int. J. Pharm. 395 (2010) 62-70; DOI: 10.1016/j.ijpharm.2010.04.035.

133. M. Kunaver, J. Zadnik and O. Planinsek, Inverse gas chromatography-A different approach to characterization of solids and liquids, Acta Chim. Slov. 51 (2004) 373-394.

134. A. Voelkel, B. Strzemiecka, K. Adamska and K. Milczewska, Inverse gas chromatography as a source of physicochemical data, J. Chromatogr. A 1216 (2009) 1551-1566; DOI: 10.1016/j.chroma. 2008.10.096.

135. S. P. Chamarthy and R. Pinal, The nature of crystal disorder in milled pharmaceutical materials, Colloid. Surfaces A 331 (2008) 68-75; DOI: 10.1016/j.colsurfa.2008.06.040.

136. O. Planinsek, J. Zadnik, M. Kunaver, S. Srcic and A. Godec, Structural evolution of indomethacin particles upon milling: time-resolved quantification and localization of disordered structure studied by IGC and DSC, J. Pharm. Sci. 99 (2010) 1968-1981; DOI: 10.1002/jps.21986.

137. M. Otsuka and N. Kaneniwa, Effect of environment on crystallinity and chemical stability in solid-state of ground cephalotin sodium during storage, Drug Dev. Ind. Pharm. 17 (1990) 909918; DOI: 10.3109/03639049109040828.

138. H. Konno and L. S. Taylor, Influence of different polymers on the crystallization tendency of molecularly dispersed amorphous felodipine, J. Pharm. Sci. 95 (2006) 2692-2705; DOI: 10.1002/ jps.20697. 
139. X. C. Tang, M. J. Pikal and L. S. Taylor, The effect of temperature on hydrogen bonding in crystalline and amorphous phases in dihydropyrine calcium channel blockers, Pharm. Res. 19 (2002) 484-490; DOI: 10.1023/A:1015199713635.

140. L. Mackin, S. Sartnurak, I. Thomas and S. Moore, The impact of low levels of amorphous material, Int. J. Pharm. 231 (2002) 213-226; DOI: 10.1016/S0378-5173(01)00880-8.

141. J. J. Seyer, P. E. Luner and M. S. Kemper, Application of diffuse reflectance near-infrared spectroscopy for determination of crystallinity, J. Pharm. Sci. 89 (2000) 1305-1316; DOI: 10.1002/ 1520-6017(200010)89:10<1305::AID-JPS8>3.0.CO;2-Q.

142. S. J. Bai, M. Rani, R. Suryanarayanan, J. F. Carpenter, R. Nayar and M. C. Manning, Quantification of glycine crystallinity by near-infrared (NIR) spectroscopy, J. Pharm. Sci. 93 (2004) 24392447; DOI:10.1002/jps.20153.

143. P. Aldridge, C. Evans, H. Ward, S. Colgan, N. Boyer and P. Gemperline, Near-IR detection of polymorphism and process-related substances, Anal. Chem. 68 (1996) 997-1002; DOI: 10.1021/ ac950993x.

144. S. Hogan and G. Buckton, The application of near infrared spectroscopy and dynamic vapor sorption to quantify low amorphous contents of crystalline lactose, Pharm. Res. 18 (2001) 112116; DOI: $10.1023 / \mathrm{A}: 1011091113734$

145. G. Buckton, E. Yonemochi, J. Hammond and A. Moffat, The use of near infra-red spectroscopy to detect changes in the form of amorphous and crystalline lactose, Int. J. Pharm. 168 (1998) 231-241; DOI: 10.1016/S0378-5173(98)00095-7.

146. M. Otsuka and H. Tanabe, Stability test for amorphous materials in humidity controlled 96-well plates by near-infrared spectroscopy, Drug Dev. Ind. Pharm. 38 (2012) 380-385; DOI: 10. 3109/03639045.2011.608680.

147. M. Otsuka, F. Kato and Y. Matsuda, Comparative evaluation of the degree of indomethacin crystallinity by chemoinfometrical Fourier-transformed near-infrared spectroscopy and conventional powder X-ray diffractometry, AAPS PharmSci 2 (2000) E9; DOI: 10.1208/ps020109.

148. P. Vandenabeele, Practical Raman Spectroscopy, Wiley, Chichosten 2013, pp. 23-80.

149. P. Karmwar, K. Graeser, K. C. Gordon, C. J. Strachan and T. Rades, Effect of different preparation methods on the dissolution behaviour of amorphous indomethacin, Eur. J. Pharm. Biopharm. 80 (2012) 459-464; DOI: 10.1016/j.ejpb.2011.10.006.

150. J. P. Boetker, V. Koradia, T. Rades and J. Rantanen, Atomic pairwise distribution function analysis of the amorphous phase prepared by different manufacturing routes, Pharmaceutics 4 (2012) 93-103 DOI: 10.3390/pharmaceutics4010093.

151. M. Savolainen, K. Kogermann, A. Heinz, J. Aaltonen, L. Peltonen, C. Strachan and J. Yliruusi, Better understanding of dissolution behaviour of amorphous drugs by in situ solid-state analysis using Raman spectroscopy, Eur. J. Pharm. Biopharm. 71 (2009) 71-79; DOI: 10.1016/j.ejpb. 2008.06.001.

152. S. Hasegawa, T. Hamaura, N. Furuyama, S. Horikawa, A. Kusai, E. Yonemochi and K. Terada, Uniformity and physical states of troglitazone in solid dispersions determined by electron probe microanalysis and microthermal analysis, Int. J. Pharm. 280 (2004) 39-46; DOI: 10.1016/j. ijpharm.2004.04.024.

153. K. Kawakami, T. Numa and Y. Ida, Assessment of amorphous content by microcalorimetry, J. Pharm. Sci. 91 (2002) 417-423; DOI: 10.1002/jps.10017.

154. G. Buckton, P. Darcy, D. Greenleaf and P. Holbrook, The use of isothermal microcalorimetry in the study of changes in crystallinity of spray-dried salbutamol sulphate, Int. J. Pharm. 116 (1995) 113-118; DOI: 10.1016/0378-5173(94)00322-V.

155. L. E. Briggner, G. Buckton, K. Bystrom and P. Darcy, The use of isothermal microcalorimetry in the study of changes in crystallinity induced during the processing of powders, Int. J. Pharm. 105 (1994) 125-135; DOI: 10.1016/0378-5173(94)90458-8. 
156. D. Giron, P. Remy, S. Thomas and E. Vilette, Quantitation of amorphicity by microcalorimetry, J. Therm. Anal. 48 (1997) 465-472; DOI: 10.1007/BF01979493.

157. J. Nishizawa, N. G. Hadjiconstantinou, G. Dimonte, P. S. Lomdahl, B. L. Holian and B. J. Alder, Pioneering work of $\mathrm{THz}$ wave and its application for molecular sciences, AIP Conference Proceedings 708 (2004) 369-375. 